\title{
Analysis of laminated composite skew shells using higher order shear deformation theory
}

\begin{abstract}
Static analysis of skew composite shells is presented by developing a $\mathrm{C}_{0}$ finite element (FE) model based on higher order shear deformation theory (HSDT). In this theory the transverse shear stresses are taken as zero at the shell top and bottom. A realistic parabolic variation of transverse shear strains through the shell thickness is assumed and the use of shear correction factor is avoided. Sander's approximations are considered to include the effect of three curvature terms in the strain components of composite shells. The $\mathrm{C}_{0}$ finite element formulation has been done quite efficiently to overcome the problem of $\mathrm{C}_{1}$ continuity associated with the HSDT. The isoparametric FE used in the present model consists of nine nodes with seven nodal unknowns per node. Since there is no result available in the literature on the problem of skew composite shell based on HSDT, present results are validated with few results available on composite plates/shells. Many new results are presented on the static response of laminated composite skew shells considering different geometry, boundary conditions, ply orientation, loadings and skew angles. Shell forms considered in this study include spherical, conical, cylindrical and hypar shells.
\end{abstract}

\section{Keywords}

skew shell, composite, higher order shear deformation theory, cylindrical, hypar, finite element method

\section{Ajay Kumar*, Anupam \\ Chakrabarti and Mrunal Ketkar}

Department of Civil Engineering, Indian Institute of Technology, Roorkee-247 667, India Phone: +91(1332)285844,

Fax.: +91(1332)275568

Received 14Jun 2012

In revised form 09 Oct 2012

*Author email: sajaydce@gmail.com

\section{INTRODUCTION}

Laminated composite shell structures are widely used in civil, mechanical, aerospace and other engineering applications. Laminated composites materials are becoming popular because of their high strength to weight and strength to stiffness ratios. The most important feature for the analysis of composite structures is that the material (composite) is weak in shear compared to extensional rigidity. Due to this reason transverse shear deformation of the composite shell has to be modeled very efficiently. 


\section{Nomenclature}

$\mathrm{a}=$ Length of the mappedshell panel parallel to x-axis in plan

$\alpha=$ Angle between skewed edge of mapped shell panel with respect to y-axis measured in plan

$\mathrm{b}=$ Width of the mapped shell panel parallel to $\mathrm{y}$-axis in plan

$\mathrm{h}=$ Total height of the shell panel

$N$ x $N=$ FE mesh divison denoted as (Number of divisions in X-direction) x (Number of divisions in Y-direction).

$\mathrm{L}=$ Total number of layers in a lamination scheme

$\mathrm{S}=$ Ratio of length to total height of shell panel $(a / h)$ 
Classical theories originally developed for thin elastic shells are based on the Love- Kirchhoff assumptions. These theories neglect the effect of transverse shear deformations. However, application of such theories to laminated composite shells where shear deformation is very significant, may lead to errors in calculating deflections, stresses and frequencies.

In subsequent development of shell theories transverse shear deformation was included in a manner where the shear strain is uniform throughout the thickness of the shell. These theories are known as first order shear deformation theory (FSDT). In this theory a shear correction factors are required for the analysis and these factors should be calculated based on the orientations of different layers in different directions.

The effects of transverse shear and normal stresses in shells were considered by Hildebrand, Reissner and Thomas [18], Lure [25], and Reissner [35]. The effect of transverse shear deformation and transverse isotropy, as well as thermal expansion through the thickness of cylindrical shells were considered by Gulati and Essenberg [16], Zukas and Vinson [43], Dong et al. [12, 13], Hsu and Wang [19], and Whitney and Sun [37, 38]. The higher-order shell theories presented in [37, 38] are based on a displacement field in which the displacements in the surface of the shell are expanded as linear functions of the thickness coordinate and the transverse displacement is expanded as a quadratic function of the thickness coordinate. These higher-order shell theories are cumbersome and computationally more demanding, because, with each additional power of the thickness co-ordinates, an additional dependent unknown is introduced into the theory.

Reddy and Liu [33] presented a simple higher-order shear deformation theory (HSDT) for the analysis of laminated shells. It contains the same dependent unknowns as in the first-order shear deformation theory (FSDT) in which the displacements of the middle surface are expanded as linear functions of the thickness coordinate and the transverse deflection is assumed to be constant through the thickness. The theory is based on a displacement field in which the displacements of the middle surface are expanded as cubic functions of the thickness coordinate and the transverse displacement is assumed to be constant through the thickness. The additional dependent unknowns introduced with the quadratic and cubic powers of the thickness coordinate are evaluated in terms of the derivatives of the transverse displacement and the rotations of the normals at the middle surface. This displacement field leads to the parabolic distribution of the transverse shear stresses (and zero transverse normal strain) and therefore no shear correction factors are used. Huang [20] presented modified Reddy's theory and further improved the accuracy. Xiao-ping [39] presented a shell theory based on Love's first-order geometric approximation and Donnell's simplification for shallow shells. The theory improves the in-plane displacement (u, v) distribution through thickness by ensuring the continuity of interlaminar transverse shear stresses and zero transverse shear strains on the surface. The theory contains then same dependent unknown and the same order of governing equations as in the first-order shear deformation theory. Without the need for shear correction factors, the theory predicts more accurate responses than first-order theory and some higher-order theories, and the solutions are very close to the elasticity solutions. However, these theories [33, 39] demand $\mathrm{C} 1$ continuity of transverse displacements during finite element implementations.

Yang [41] developed a higher-order shell element with three constant radii of curvature, two principal radii, orthogonal to each other and one twist radius. The displacement functions $u, v$ and $\mathrm{w}$ are composed of products of one-dimensional Hermite interpolation formulae. Shu and Sun [40] 
developed an improved higher-order theory for laminated composite plates. This theory satisfies the stress continuity across each layer interface and also includes the influence of different materials and ply-up patterns on the displacement field. Liew and Lim [24] proposed a higher-order theory by considering the Lame' parameter $(1+\mathrm{z} / \mathrm{Rx})$ and $(1+\mathrm{z} / \mathrm{Ry})$ for the transverse strains, which were neglected by Reddy and Liu [33]. This theory accounts for cubic distribution (non-even terms) of the transverse shear strains through the shell thickness in contrast with the parabolic shear distribution (even-terms) of Reddy and Liu [33]. Kant and Khare [21] presented a higher-order facet quadrilateral composite shell element. Bhimaraddi [4], Mallikarjuna and Kant [26], Cho et al. [8] are among the others to develop higher-order shear deformable shell theory. It is observed that except for the theory of Yang [41], remaining higher-order theories do not account for twist curvature $(1 / \mathrm{Rxy})$, which is essential while analyzing shell forms like hypar and conoid shells.

Analyses of composite shell panels were carried out by many researchers $[1,4,6,7,9,14,15,22$, 24, 27, 29, 30, 33 and 36] in the past few decades mainly based on FSDT.

However, application of higher-order theory for studying the behavior of laminated composite shells with the combination of all three radii of curvature is very limited in literature. Pradyumna and Bandyopadhyay [31] studied the behavior of laminated composite shells based on a higher-order shear deformation theory (HSDT) developed by Kant and Khare [21]. They also [21] also extended the theory to the shells to include all three radii of curvature. However, this theory [21] contains some nodal unknowns which are not having any physical significance and therefore, incorporation of appropriate boundary conditions becomes a problem.

It is also observed that there is no literature available on the analysis of composite skew shell using HSDT while very few publications are available on the problem using FSDT [17] for isotropic materials only.

In view of the above, a new finite element model has been developed in the present study for static analysis of composite skew shell panels using a simple higher order shear deformation theory [33]. The problem of $\mathrm{C} 1$ continuity associated with theory has been overcome in this model and an existing $\mathrm{C} 0$ isoparametric finite element has been utilized for this purpose. The element contains nine nodes with seven nodal unknowns at each node. The analysis has been performed considering shallow shell assumptions. The effect of all the three radii of curvature is also included in the formulation. The present finite element model based on HSDT is applied to solve many problems of composite skew shells considering different shell geometries, boundary conditions, loadings and other parameters. The present results are also validated with some published results.

\section{THEORY AND FORMULATION}

A laminated shell element made of a finite number of uniformly thick orthotropic layers oriented arbitrarily with respect to the shell co-ordinates (x, y, z) is shown in Figure 1. The reference plane (i.e., mid plane) is defined at at $\mathrm{z}=0$.

Latin American Journal of Solids and Structures 10(2013) $891-919$ 


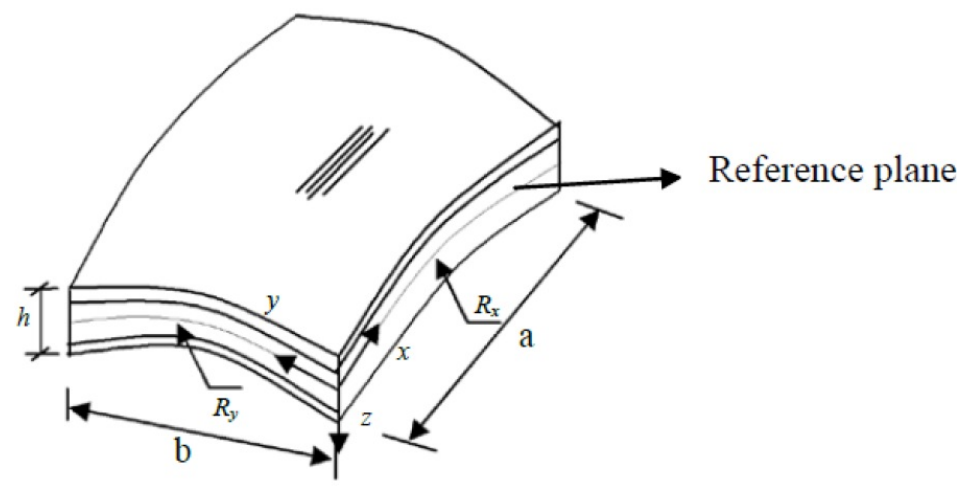

Figure 1 Laminated composite doubly curved shell element

In the present formulation the in-plane displacement components $\mathrm{u}(\mathrm{x}, \mathrm{y}, \mathrm{z})$ and $\mathrm{v}(\mathrm{x}, \mathrm{y}, \mathrm{z})$ at any point in the shell space are expanded in Taylor's series in terms of the thickness co- ordinates while the transverse displacement, $\mathrm{w}(\mathrm{x}, \mathrm{y})$ is taken as constant throughout the shell thickness. As the transverse shear stresses actually vary parabolically through the shell thickness the in-plane displacement fields are expanded as cubic functions of the thickness co-ordinate. The displacement fields are assumed in the form as given by Reddy [32] which satisfy the abovecriteria and may be expressed as below:

$$
\begin{gathered}
\mathrm{u}(\mathrm{x}, \mathrm{y}, \mathrm{z})=\mathrm{u}(\mathrm{x}, \mathrm{y})+\mathrm{z} \vartheta(\mathrm{x}, \mathrm{y})+\mathrm{z}^{2} \xi(\mathrm{x}, \mathrm{y})+\mathrm{z}^{3} \zeta(\mathrm{x}, \mathrm{y}) \\
\mathrm{v}(\mathrm{x}, \mathrm{y}, \mathrm{z})=\mathrm{v}(\mathrm{x}, \mathrm{y})+\mathrm{z} \vartheta(\mathrm{x}, \mathrm{y})+\mathrm{z}^{2} \xi(\mathrm{x}, \mathrm{y})+\mathrm{z}^{3} \zeta(\mathrm{x}, \mathrm{y}) \\
\mathrm{w}(\mathrm{x}, \mathrm{y})=\mathrm{w}_{0}(\mathrm{x}, \mathrm{y})
\end{gathered}
$$

where $\mathrm{u}, \mathrm{v}$ and $\mathrm{w}$ are the displacements of a general point $(\mathrm{x}, \mathrm{y}, \mathrm{z})$ in an element of the laminate along $\mathrm{x}, \mathrm{y}$ and $\mathrm{z}$ directions, respectively. The parameters $\mathrm{u}_{0}, \mathrm{v}_{0}$, and $\mathrm{w}_{0}$ denote the displacements of a point $(\mathrm{x}, \mathrm{y})$ on the mid plane, and and are the rotations of normals with respect to the mid plane about the $\mathrm{y}$ and $\mathrm{x}$ axes, respectively. The functions $\xi_{\mathrm{x}}, \zeta_{\mathrm{x}}, \xi_{\mathrm{y}}$ and $\zeta_{\mathrm{y}}$ can be determined using the conditions that the transverse shear strains, $\gamma_{x z}$ and $\gamma_{y z}$ vanish at the top and bottom surfaces of the shell. We have

$$
\begin{aligned}
& \gamma_{x z}=\frac{\partial u}{\partial z}+\frac{\partial w}{\partial x}=\theta_{x}+2 z \xi_{x}+3 z^{2} \zeta_{x}+\frac{\partial w}{\partial x} \\
& \gamma_{y z}=\frac{\partial v}{\partial z}+\frac{\partial w}{\partial y}=\theta_{y}+2 z \xi_{y}+3 z^{2} \zeta_{y}+\frac{\partial w}{\partial y}
\end{aligned}
$$

Setting $\gamma_{x z}\left(x, y, \pm \frac{h}{2}\right)$ and $\gamma_{y z}\left(x, y, \pm \frac{h}{2}\right)$ to zero, we obtain 


$$
\begin{gathered}
\xi_{x}=0, \quad \xi_{y}=0 \\
\zeta_{x}=-\frac{4}{3 h^{2}}\left(\theta_{x}+\frac{\partial w}{\partial x}\right), \zeta_{y}=-\frac{4}{3 h^{2}}\left(\theta_{y}+\frac{\partial w}{\partial y}\right)
\end{gathered}
$$

The displacement field in equation (1) becomes

$$
\begin{gathered}
u=u_{0}+z \theta_{x}\left(1-\frac{4 z^{2}}{3 h^{2}}\right)-\frac{4 z^{3}}{3 h^{2}}\left(\frac{\partial w}{\partial x}\right)=u_{0}+z \theta_{x}\left(1-\frac{4 z^{2}}{3 h^{2}}\right)-\frac{4 z^{3}}{3 h^{2}} \psi_{x}^{*} \\
v=v_{0}+z \theta_{y}\left(1-\frac{4 z^{2}}{3 h^{2}}\right)-\frac{4 z^{3}}{3 h^{2}}\left(\frac{\partial w}{\partial y}\right)=v_{0}+z \theta_{y}\left(1-\frac{4 z^{2}}{3 h^{2}}\right)-\frac{4 z^{3}}{3 h^{2}} \psi_{y}^{*} \\
w=w_{0}
\end{gathered}
$$

The linear strain-displacement relations according to Sanders' approximation are:

$$
\begin{gathered}
\varepsilon_{x}=\frac{\partial u}{\partial x}+\frac{w}{R_{x}}, \varepsilon_{y}=\frac{\partial v}{\partial y}+\frac{w}{R_{y}}, \gamma_{x y}=\frac{\partial v}{\partial x}+\frac{\partial u}{\partial y}+\frac{2 w}{R_{x y}} \\
\gamma_{x z}=\frac{\partial u}{\partial z}+\frac{\partial w}{\partial x}-A_{1} \frac{u}{R_{x}}-A_{1} \frac{v}{R_{x y}} \gamma_{y z}=\frac{\partial v}{\partial z}+\frac{\partial w}{\partial y}-A_{1} \frac{v}{R_{y}}-A_{1} \frac{u}{R_{x y}}
\end{gathered}
$$

Substituting equation (4) in equation (5):

$$
\begin{gathered}
\varepsilon_{x}=\varepsilon_{x 0}+z K_{x}\left(1-\frac{4 z^{2}}{3 h^{2}}\right)-\frac{4 z^{3}}{3 h^{2}} K_{x}^{*} \\
\varepsilon_{y}=\varepsilon_{y 0}+z K_{y}\left(1-\frac{4 z^{2}}{3 h^{2}}\right)-\frac{4 z^{3}}{3 h^{2}} K_{y}^{*} \\
\gamma_{x y}=\gamma_{x y 0}+z K_{x y}\left(1-\frac{4 z^{2}}{3 h^{2}}\right)-\frac{4 z^{3}}{3 h^{2}} K_{x y}^{*} \\
\gamma_{x z}=\phi_{x}+z K_{x z}\left(1-\frac{4 z^{2}}{3 h^{2}}\right)-\frac{4 z^{3}}{3 h^{2}} K_{x z}^{*}-\frac{4 z^{3}}{3 h^{2}} K_{x z}^{* *} \\
\gamma_{y z}=\phi_{y}+z K_{y z}\left(1-\frac{4 z^{2}}{3 h^{2}}\right)-\frac{4 z^{3}}{3 h^{2}} K_{y z}^{*}-\frac{4 z^{3}}{3 h^{2}} K_{y z}^{* *}
\end{gathered}
$$


where,

$$
\begin{gathered}
\left\{\varepsilon_{x 0}, \varepsilon_{y 0}, \gamma_{x y 0}\right\}=\left\{\frac{\partial u_{0}}{\partial x}+\frac{w_{0}}{R_{x}}, \frac{\partial v_{0}}{\partial y}+\frac{w_{0}}{R_{y}}, \frac{\partial u_{0}}{\partial y}+\frac{\partial v_{0}}{\partial x}+\frac{2 w_{0}}{R_{x y}}\right\} \\
\left\{\phi_{x}, \phi_{y}\right\}=\left\{\frac{\partial w}{\partial x}+\theta_{x}-A_{1} \frac{u_{0}}{R_{x}}-A_{1} \frac{v_{0}}{R_{x y}}, \frac{\partial w}{\partial y}+\theta_{y}-A_{1} \frac{v_{0}}{R_{y}}-A_{1} \frac{u_{0}}{R_{x y}}\right\} \\
\left\{K_{x}, K_{y}, K_{x y}, K_{x}^{*}, K_{y}^{*}, K_{x y}^{*}\right\}=\left\{\frac{\partial \theta_{x}}{\partial x}, \frac{\partial \theta_{y}}{\partial y}, \frac{\partial \theta_{x}}{\partial y}+\frac{\partial \theta_{y}}{\partial x}, \frac{\partial \psi_{x}^{*}}{\partial x}, \frac{\partial \psi_{y}^{*}}{\partial y}, \frac{\partial \psi_{x}^{*}}{\partial y}+\frac{\partial \psi_{y}^{*}}{\partial x}\right\} \\
\left\{K_{x z}, K_{y z}, K_{x z}^{*}, K_{y z}^{*}\right\}=\left\{-A_{1} \frac{\theta_{x}}{R_{x}}-A_{1} \frac{\theta_{y}}{R_{x y}},-A_{1} \frac{\theta_{y}}{R_{y}}-A_{1} \frac{\theta_{x}}{R_{x y}},-A_{1} \frac{\psi_{x}^{*}}{R_{x}}-A_{1} \frac{\psi_{y}^{*}}{R_{x y}},-A_{1} \frac{\psi_{y}^{*}}{R_{y}}-A_{1} \frac{\psi_{x}^{*}}{R_{x y}}\right\} \\
\left\{K_{x z}^{* *}, K_{y z}^{* *}\right\}=\left\{\theta_{x}+\psi_{x}^{*}, \theta_{y}+\psi_{y}^{*}\right\}
\end{gathered}
$$

$A_{1}$ is a tracer by which the analysis can be reduced to that of shear deformable Love's first approximation. $A_{1}$ is important factor as it helps to incorporate the shear part which plays a critical role in failure analysis of composite laminates. Hence, $A_{1}$ must be chosen cautiously accordingly to shear deformation theory used to analyze the composites.

The constitutive relations for a typical lamina $(\mathrm{k}-\mathrm{th})$ with reference to the material axis may be written as:

$$
\left\{\begin{array}{l}
\sigma_{1} \\
\sigma_{2} \\
\tau_{12} \\
\tau_{13} \\
\tau_{23}
\end{array}\right\}_{k}=\left[\begin{array}{ccccc}
Q_{11} & Q_{12} & 0 & 0 & 0 \\
Q_{12} & Q_{22} & 0 & 0 & 0 \\
0 & 0 & Q_{66} & 0 & 0 \\
0 & 0 & 0 & Q_{44} & 0 \\
0 & 0 & 0 & 0 & Q_{55}
\end{array}\right]_{k}\left(\begin{array}{l}
\varepsilon_{1} \\
\varepsilon_{2} \\
\gamma_{12} \\
\gamma_{13} \\
\gamma_{23}
\end{array}\right\}_{k}
$$

or, in matrix form:

$$
\{\sigma\}_{k}=[Q]_{k}\{\varepsilon\}_{k}
$$

where, $\mathrm{Q}_{11}=\mathrm{E}_{1} / 1-\nu_{12} \nu_{21}, \mathrm{Q}_{12}=\nu_{12} \mathrm{E}_{2} / 1-\nu_{12} \nu_{21}, \mathrm{Q}_{22}=\mathrm{E}_{2} / 1-\nu_{12} \nu_{21}, \mathrm{Q}_{66}=\mathrm{G}_{12}, \mathrm{Q}_{44}=\mathrm{G}_{13}$, $\mathrm{Q}_{55}=\mathrm{G}_{23}$ and $\frac{v_{12}}{\mathrm{E}_{1}}=\frac{v_{21}}{\mathrm{E}_{2}}$

After that, we need to transform the lamina stiffness matrix into a global form using the transformed coefficient. In global form, lamina with different angles and thickness of each layer 
are computed. Hence, the transformed stiffness matrix $\bar{Q}_{i j}$ can be calculated. The stress-strain relations for a lamina about the structure axis system ( $\mathrm{x}, \mathrm{y}, \mathrm{z})$ may be written as below after doing the necessary transformation,

$$
\left\{\begin{array}{l}
\sigma_{x} \\
\sigma_{y} \\
\tau_{x y} \\
\tau_{x z} \\
\tau_{y z}
\end{array}\right\}_{k}=\left[\begin{array}{ccccc}
\bar{Q}_{11} & \bar{Q}_{12} & 0 & 0 & 0 \\
\bar{Q}_{12} & \bar{Q}_{22} & 0 & 0 & 0 \\
0 & 0 & \bar{Q}_{66} & 0 & 0 \\
0 & 0 & 0 & \bar{Q}_{44} & 0 \\
0 & 0 & 0 & 0 & \bar{Q}_{55}
\end{array}\right]_{k}\left\{\begin{array}{l}
\varepsilon_{1} \\
\varepsilon_{2} \\
\varepsilon_{12} \\
\varepsilon_{13} \\
\varepsilon_{23}
\end{array}\right\}_{k}
$$

Integrating the stresses through the laminate thickness, the resultant forces and moments acting on the laminate may be obtained as below,

$$
\begin{gathered}
{[N]=\left[\begin{array}{l}
N_{x} \\
N_{y} \\
N_{x y}
\end{array}\right]=\sum_{k=1}^{N_{L}} \int_{Z_{k}} z_{k+1}\left[\begin{array}{l}
\sigma_{x} \\
\sigma_{y} \\
\tau_{x y}
\end{array}\right] d z} \\
{[M]=\left[\begin{array}{cc}
M_{x} & M_{x}^{*} \\
M_{y} & M_{y}^{*} \\
M_{x y} & M_{x y}^{*}
\end{array}\right]=\sum_{k=1}^{N_{L}} \int_{Z_{k}}^{z_{k+1}}\left[\begin{array}{l}
\sigma_{x} \\
\sigma_{y} \\
\tau_{x y}
\end{array}\right]\left[z, z^{3}\right] d z} \\
{\left[Q, S, S^{*}, S^{* *}\right]=\left[\begin{array}{lll}
Q_{x} & S_{x} & S_{x}^{*} \\
Q_{y} & S_{y} & S_{y}^{*}
\end{array}\right]\left[\begin{array}{cccc}
Q_{x} & S_{x} & S_{x}^{*} & S_{x}^{* *} \\
Q_{y} & S_{y} & S_{y}^{*} & S_{y}^{* *}
\end{array}\right]=\sum_{k=1}^{N_{L}} \int_{Z_{k}}^{Z_{k}+1}\left[\begin{array}{l}
\tau_{x z} \\
\tau_{y z}
\end{array}\right]\left[1, z, z^{2}, z^{3}\right] d z}
\end{gathered}
$$

or $\{\bar{\sigma}\}=[\bar{D}]\{\bar{\varepsilon}\}$, where

$$
\begin{aligned}
& \{\bar{\sigma}\}=\left[N_{x}, N_{y}, N_{x y}, M_{x}, M_{y}, M_{x y}, M_{x}^{*}, M_{y}^{*}, M_{x y}^{*}, \theta_{x}, \theta_{y}, S_{x}, S_{y}, S_{x}^{*}, S_{y}^{*}, S_{x}^{* *}, S_{y}^{* *}\right]^{T} \\
& \{\bar{\varepsilon}\}=\left[\varepsilon_{x 0}, \varepsilon_{y 0}, \gamma_{x y 0}, K_{x}, K_{y}, K_{x y}, K_{x}^{*}, K_{y}^{*}, K_{x y}^{*}, \phi_{x}, \phi_{y}, K_{x z}, K_{y z}, K_{x z}^{*}, K_{y z}^{*}, K_{x z}^{* *}, K_{y z}^{* *}\right]^{T}
\end{aligned}
$$

and $[\bar{D}]$ is the rigidity matrix of size $17 \times 17$.

Latin American Journal of Solids and Structures 10(2013) 891 - 919 


\subsection{Finite element formulation}

A nine-noded isoparametric $\mathrm{C}_{0}$ element with seven unknowns per node developed by Singh et. al [34] is used in the present finite element model. The nodal unknown vector $\{d\}$ on the midsurface of a typical element is given by:

$$
\{d\}=\sum_{i=1}^{9} N_{i}(x, y)\left\{d_{i}\right\}
$$

where $\left\{d_{i}\right\}$ is the nodal unknown vector corresponding to node $i$ and $N_{i}$ is the interpolating shape function associated with the node $i$. The problem of a skew shell as shown in Figure [2] is studied by using the proposed finite element model.

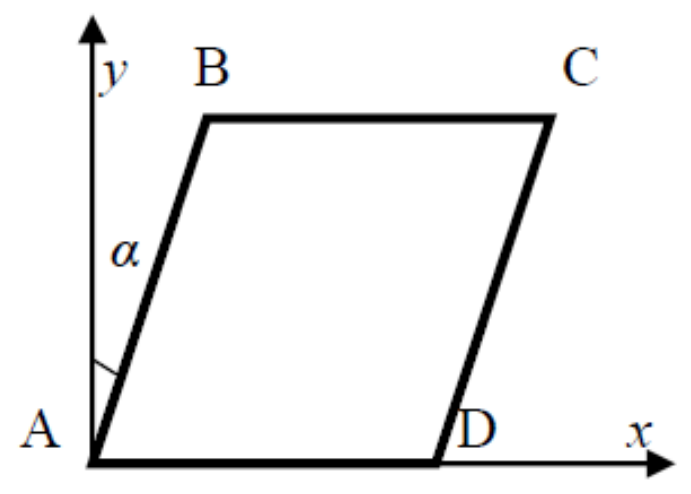

Figure 2 Mappedskewshell panel

As the sides $\mathrm{AB}$ and $\mathrm{DC}$ are inclined to global axis by an angle, $\alpha$, necessary transformation is made to express the degrees of freedom of the nodes on these two sides.

After getting the generalized nodal unknown vector $\{d\}$ within an element, the generalized midsurface strains at any point of the shell (Eq.: 6), can be expressed in terms of global displacements as shown below,

$$
\{\bar{\varepsilon}\}=\sum_{i=1}^{9}\left[B_{i}\right]\left\{d_{i}\right\}
$$

where $\left[B_{i}\right]$ is the differential operator matrix of interpolation functions which may be obtained from Equation (6).

The element stiffness matrix for an element (say, $e$-th), which includes membrane, flexure, thetransverse shear effects and their couplings may be expressed by the following equation:

$$
\left[K_{e}\right]=\int_{-1}^{1} \int_{-1}^{1}[B]^{T}[D][B] j d r d s
$$


A $3 \times 3$ Gaussian Quadrature scheme has been used in all numerical integrations. The element matrices are then assembled to obtain the global stiffness matrix, $[K]$ by following the standard procedure of finite element method [10].

\section{RESULTS AND DISCUSSION}

In this section many problems of laminated composite shells are solved for normal as well as skew configurations using the present finite element model based on HSDT. A computer code is developed based on the above formulation for the implementation of the above model. As there is no result available in the literature in the present problem of laminated composite skew shell, the results obtained by the proposed model are validated by some published results on laminated composite shells of normal geometry. A mapped skew shell is shown in Figure 2. To validate the results for skew geometry, the present finite element results are first compared with some results of isotropic and composite skew plates. Then the results obtained by the present model are compared with some limited published results of skew shells using isotropic material. Many new results are generated for the benefit of the future researchers. The shell forms mainly considered for validation are spherical, conical, cylindrical and hypar shells while the problems of skew shells are restricted to cylindrical and hypar geometry.

The elastic properties of the lamina with respective to the material axes has been taken as $E_{1} / E_{2}=25, G_{12}=G_{13}=0.5 E_{2}, G_{23}=0.2 E_{2}$ and $\nu_{12}=0.25$, unless mentioned otherwise.

The following boundary conditions are used in the present analysis:

1. Simply supported (SSSS):

$$
\begin{aligned}
& v=w=\theta_{y}=\psi_{y}=0, \text { at } x=0, \mathrm{a} \\
& u=w=\theta_{x}=\psi_{x}=0 \text { at } y=0, \mathrm{~b}
\end{aligned}
$$

\section{Clamped (CCCC):}

$u=v=w=\theta_{x}=\theta_{y}=\psi_{x}=\psi_{y}=0$, at $x=0$, a and $y=0, \mathrm{~b}$

\section{Simply supported-Clamped (SCSC):}

$$
\begin{aligned}
& v=w=\theta_{y}=\psi_{y}=0, \text { at } x=0 \text { and } u=w=\theta_{x}=\psi_{x}=0 \text { at } y=0 \\
& u=v=w=\theta_{x}=\theta_{y}=\psi_{x}=\psi_{y}=0, \text { at } x=a \text { and at } y=b
\end{aligned}
$$

\subsection{Validation of the Present Formulation}

In order to validate the present formulation, some problems are solved which are already reported in the literature.

\subsubsection{Convergence Study}

Convergence study is carried out in order to determine the required mesh size $N \times N$ at which the displacement values converge. Table 1 shows the convergence of the results of a simply supported cross-ply spherical shell subjected to uniform loading with $a / b=1$ and $R_{x}=R_{y}=R$ with the 
orthotropic elastic properties as mentioned earlier. Three different lamination schemes $\left(0^{0} / 90^{0}\right.$, $0^{0} / 90^{0} / 90^{0}$ and $\left.0^{0} / 90^{0} / 90^{\circ} / 0^{0}\right)$ are considered.

Table 1 Non-dimensional central deflections $(\bar{w})$ of a simply supported cross-ply laminated spherical shell under uniform load

\begin{tabular}{|c|c|c|c|c|c|c|c|}
\hline \multirow[t]{3}{*}{$R / a$} & \multirow[t]{3}{*}{ Theory } & \multicolumn{6}{|c|}{ Lamination scheme } \\
\hline & & \multicolumn{2}{|c|}{$0^{0} / 90^{\circ}$} & \multicolumn{2}{|l|}{$0^{\circ} / 90^{\circ} / 0^{0}$} & \multicolumn{2}{|c|}{$0^{0} / 90^{\circ} / 90^{\circ} / 0^{\circ}$} \\
\hline & & $a / h=100$ & $a / h=10$ & $a / h=100$ & $a / h=10$ & $a / h=100$ & $a / h=10$ \\
\hline \multirow{6}{*}{5} & Present $(4 \times 4)$ & 1.7884 & 17.6364 & 1.5295 & 10.4708 & 1.5531 & 10.5789 \\
\hline & Present $(6 \times 6)$ & 1.7668 & 17.6685 & 1.5168 & 10.4189 & 1.5426 & 10.5578 \\
\hline & Present $(8 \times 8)$ & 1.7594 & 17.6797 & 1.5141 & 10.4165 & 1.5389 & 10.5590 \\
\hline & Present $(12 \times 12)$ & 1.7527 & 17.6845 & 1.5116 & 10.4153 & 1.5355 & 10.5592 \\
\hline & Present $(16 \times 16)$ & 1.7527 & 17.6845 & 1.5116 & 10.4153 & 1.5355 & 10.5592 \\
\hline & Reddy and Liu[33] & 1.7519 & 17.566 & 1.5092 & 10.332 & 1.5332 & 10.476 \\
\hline 3 & Present $(12 \times 12)$ & 0.6441 & 15.5328 & 0.6223 & 9.6498 & 0.6245 & 9.7766 \\
\hline 4 & Present $(12 \times 12)$ & 1.1410 & 16.9436 & 1.0441 & 10.1608 & 1.0559 & 10.2989 \\
\hline \multirow{2}{*}{10} & Reddy and Liu[33] & 5.5388 & 18.744 & 3.6426 & 10.752 & 3.7195 & 10.904 \\
\hline & Present $(12 \times 12)$ & 5.5255 & 18.7762 & 3.6438 & 10.7743 & 3.7164 & 10.9266 \\
\hline \multirow{2}{*}{20} & Reddy and Liu[33] & 11.268 & 19.064 & 5.5503 & 10.862 & 5.666 & 11.017 \\
\hline & Present $(12 \times 12)$ & 11.1806 & 19.0699 & 5.5321 & 10.8678 & 5.6425 & 11.0223 \\
\hline \multirow{2}{*}{50} & Reddy and Liu[33] & 15.711 & 19.155 & 6.4895 & 10.893 & 6.6234 & 11.049 \\
\hline & Present $(12 \times 12)$ & 15.4844 & 19.1537 & 6.4394 & 10.8942 & 6.5726 & 11.0493 \\
\hline \multirow{2}{*}{100} & Reddy and Liu[33] & 16.642 & 19.168 & 6.6496 & 10.898 & 6.7866 & 11.053 \\
\hline & Present $(12 \times 12)$ & 16.3754 & 19.1658 & 6.6083 & 10.8980 & 6.7455 & 11.0532 \\
\hline
\end{tabular}

The mesh divison parameter $N$ is varied from 4 to 16 . It may be observed in Table 1 , that the values of non-dimensional central deflections, $\bar{w}=\left(-w h^{3} E_{2} / q a^{4}\right)$ converge for $N=12$. All subsequent analysis is carried out using the uniform mesh divison $12 \mathrm{X} \mathrm{12}$. It is found that the present results are in good agreement with HSDT results of Reddy and Liu [33].

\subsubsection{Comparison of Results}

\subsubsection{Cross-ply laminated spherical shell}

A cross-ply laminated spherical shell with $a / b=1$ and $R_{x}=R_{y}=R$ with simply supported boundaries subjected to sinusoidal loading $\left(q=q_{0} \sin \frac{\pi x}{a} \sin \frac{\pi y}{b}\right)$ is considered for the analysis. This problem is earlier solved by Reddy and Liu [33]. The lamination schemes are taken as in the previous example. It is found that the present results are in close agreement with the results of Reddy and Liu [33] based on HSDT. The non-dimensional central displacements are obtained as, $\bar{w}=\left(-\frac{w h^{3} e_{2}}{q a^{4}}\right) 10^{3}$. 
Table 2 Non-dimensional central deflections of simply supported cross-ply laminated spherical shells under sinusoidally distributed load $\left(a / b=1, R_{x}=R_{y}=R\right)$

\begin{tabular}{|c|c|c|c|c|c|c|c|}
\hline \multirow{3}{*}{$R / a$} & \multirow{3}{*}{ Theory } & \multicolumn{6}{|c|}{ Lamination Scheme } \\
\hline & & \multicolumn{2}{|l|}{$0^{0} / 90^{0}$} & \multicolumn{2}{|l|}{$0^{0} / 90^{0} / 0^{0}$} & \multicolumn{2}{|c|}{$0^{0} / 90^{0} / 90^{0} / 0^{0}$} \\
\hline & & $a / h=100$ & $a / h=10$ & $a / h=100$ & $a / h=10$ & $a / h=100$ & $a / h=10$ \\
\hline \multirow{2}{*}{5} & Reddy and Liu[33] & 1.1937 & 11.166 & 1.0321 & 6.7688 & 1.0264 & 6.7865 \\
\hline & Present & 1.1907 & 11.2403 & 1.0321 & 6.8201 & 1.0254 & 6.8380 \\
\hline \multirow{2}{*}{10} & Reddy and Liu[33] & 3.5733 & 11.896 & 2.4099 & 7.0325 & 2.4024 & 7.0536 \\
\hline & Present & 3.5378 & 11.9161 & 2.4020 & 7.0459 & 2.3866 & 7.0670 \\
\hline \multirow{2}{*}{20} & Reddy and Liu[33] & 7.1236 & 12.094 & 3.6170 & 7.1016 & 3.6133 & 7.1237 \\
\hline & Present & 7.0046 & 12.0978 & 3.5717 & 7.1047 & 3.5603 & 7.1267 \\
\hline \multirow{2}{*}{50} & Reddy and Liu[33] & 9.8692 & 12.150 & 4.2071 & 7.1212 & 4.2071 & 7.1436 \\
\hline & Present & 9.5681 & 12.1498 & 4.1249 & 7.1213 & 4.1284 & 7.1436 \\
\hline \multirow{2}{*}{100} & Reddy and Liu[33] & 10.444 & 12.158 & 4.3074 & 7.1240 & 4.3082 & 7.1464 \\
\hline & Present & 10.1042 & 12.1571 & 4.2603 & 7.1237 & 4.2418 & 7.1459 \\
\hline
\end{tabular}

\subsubsection{Conical shell with different boundary conditions}

A laminated $\left(0^{0} / 90^{0} / 0^{0}\right)$ conical shell panel is considered in this example with a slant edge $L$, radii at top and bottom $R_{t}$ and $R_{b}$, respectively. The shell is subjected to uniform lateral pressure p. $12 \mathrm{X} 12 \mathrm{mesh}$ is used to discretise the shell. The material properties considered are as follows: $E_{L}=2.0 \times 10^{11} \mathrm{~Pa}, E_{L} / E_{T}=2,10,20$ and $30, G_{12}=G_{13}=0.5 \times E_{T,} G_{23}=0.2 \times E_{T,} \nu_{12}=\nu_{13}=\nu_{23}$ $=0.25$.

The central deflections (Table 3) based on the present theory were found to be in good agreement with those obtained by Bhaskar and Varadan [3] based on HSDT for clamped boundary conditions. New results for boundary conditions like SSSS, SSCC and SCSC are also presented in Table 3. It can be observed that as the ratio $E_{L} / E_{T}$ increases the deflection values decrease. On the other hand as the ratio $R_{b} / h$ is increased from 10 to 100 there is considerable decrease in deflection. The geometry of conical shell is as shown in Figure [3]. 

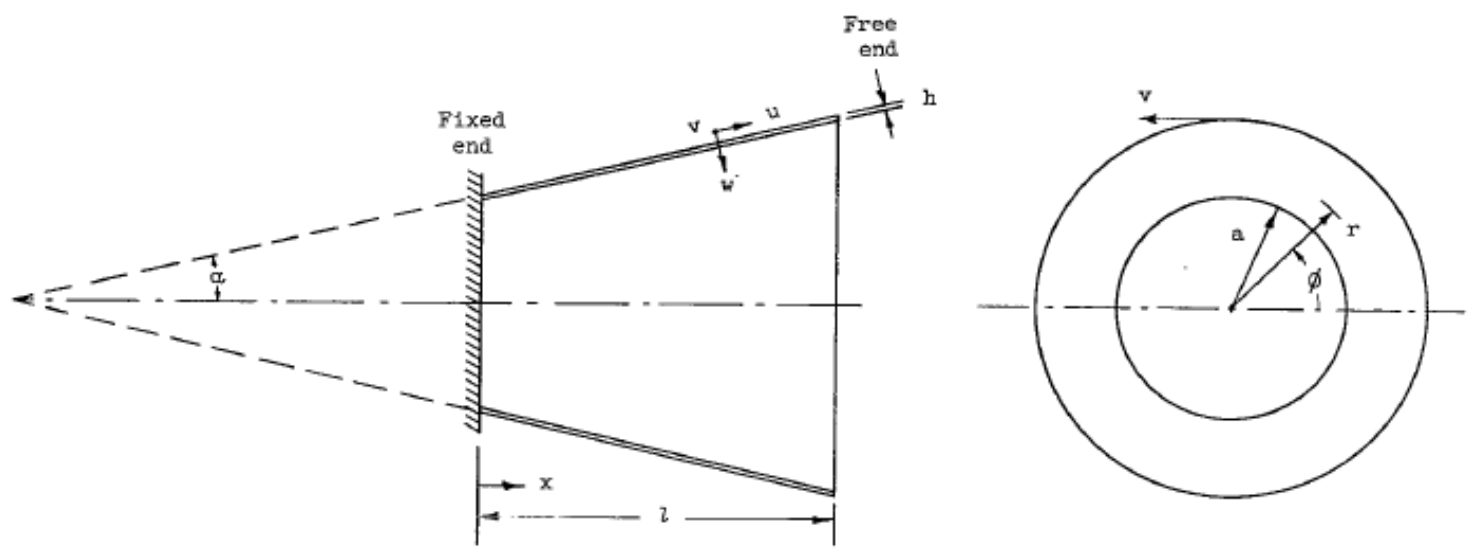

Figure 3 Conical Shell panels

Table 3 Non-dimensionalized central deflection $\bar{w}=100\left(E_{T} h^{3} w / p L^{4}\right)$ of a $\left(0^{0} / 90^{0} / 0^{0}\right)$ conical shell panel $\left(R_{t}=0.8 R_{b}, L=R_{b}, R_{b} / h=10\right)$

\begin{tabular}{|c|c|c|c|c|c|c|}
\hline \multirow{2}{*}{ Boundary condition } & \multirow{2}{*}{$R_{b} / h$} & \multirow{2}{*}{ Theory } & \multicolumn{4}{|c|}{$E_{L} / E_{T}$} \\
\hline & & & 2 & 10 & 20 & 30 \\
\hline \multirow{3}{*}{$\mathrm{CCCC}$} & \multirow{2}{*}{10} & Bhaskar and Varadan [3] & 0.3646 & 0.1270 & 0.0751 & 0.0538 \\
\hline & & Present & 0.3612 & 0.1318 & 0.0774 & 0.0551 \\
\hline & 100 & Present & 0.0043 & 0.0015 & 0.0008 & 0.0005 \\
\hline \multirow[t]{2}{*}{$S S S S$} & 10 & Present & 0.8517 & 0.4946 & 0.3910 & 0.3476 \\
\hline & 100 & Present & 0.0095 & 0.0083 & 0.0077 & 0.0075 \\
\hline \multirow{2}{*}{$\mathrm{SSCC}$} & 10 & Present & 0.4494 & 0.1765 & 0.1131 & 0.8546 \\
\hline & 100 & Present & 0.0062 & 0.0026 & 0.0015 & 0.0011 \\
\hline \multirow{2}{*}{ SCSC } & 10 & Present & 0.5718 & 0.3036 & 0.2441 & 0.2206 \\
\hline & 100 & Present & 0.0073 & 0.0053 & 0.0046 & 0.0043 \\
\hline
\end{tabular}

\subsubsection{Cylindrical shell}

\subsection{Cross-ply cylindrical shell}

Simply supported three-ply $\left(0^{0} / 90^{0} / 0^{0}\right)$, four-ply $\left(0^{0} / 90^{0} / 0^{0} / 90^{0}\right)$ and five-ply $\left(0^{0} / 90^{0} / 0^{0} / 90^{0} / 0^{0}\right)$ laminated cylindrical shells with $R_{1} / a=4$ and $b / a=3$ is considered in this example. Taking sinusoidal variation of loading $\left(q=q_{0} \sin \frac{\pi x}{a} \sin \frac{\pi y}{b}\right)$ on the shells, the central deflections obtained by thepresent model are compared with the results of Reddy and Liu [33]. 
Table 4 Non-dimensional central deflection $\bar{w}=100\left(E_{T} w / q h S^{4}\right)$ of simply supported laminated cylindrica Ishell panel $\left(R_{1} / a=4, a / h=10\right)$

\begin{tabular}{|c|c|c|c|c|c|c|c|}
\hline \multirow{3}{*}{$R_{1} / a$} & \multirow{3}{*}{$a / h$} & \multicolumn{6}{|c|}{ Lamination Scheme } \\
\hline & & \multicolumn{2}{|c|}{$0^{0} / 90^{0} / 0^{0}$} & \multicolumn{2}{|c|}{$0^{0} / 90^{0} / 0^{0} / 90^{0} / 0^{0}$} & \multicolumn{2}{|c|}{$0^{0} / 90^{0} / 0^{0} / 90^{0}$} \\
\hline & & Reddy [33] & Present & Reddy [33] & Present & Reddy [33] & Present \\
\hline \multirow{3}{*}{4} & 5 & 1.944 & 1.9218 & 1.896 & 1.8722 & 2.494 & 2.4505 \\
\hline & 10 & 0.8712 & 0.8720 & 0.931 & 0.9304 & 1.441 & 1.4350 \\
\hline & 100 & - & 0.4562 & - & 0.5312 & - & 0.8468 \\
\hline \multirow{3}{*}{10} & 5 & - & 1.9026 & - & 1.8552 & - & 2.4377 \\
\hline & 10 & - & 0.8637 & - & 0.9227 & - & 1.4289 \\
\hline & 100 & - & 0.4965 & - & 0.5921 & - & 1.0336 \\
\hline \multirow{3}{*}{20} & 5 & - & 1.8997 & - & 1.8527 & - & 2.4376 \\
\hline & 10 & - & 0.8625 & - & 0.9216 & - & 1.4289 \\
\hline & 100 & - & 0.5038 & - & 0.6017 & - & 1.0678 \\
\hline \multirow{3}{*}{50} & 5 & - & 1.8990 & - & 1.8521 & - & 2.4385 \\
\hline & 10 & - & 0.8621 & - & 0.9213 & - & 1.4293 \\
\hline & 100 & - & 0.5055 & - & 0.6053 & - & 1.0764 \\
\hline \multirow{3}{*}{100} & 5 & - & 1.9012 & - & 1.8520 & - & 2.4390 \\
\hline & 10 & - & 0.8621 & - & 0.9213 & - & 1.4295 \\
\hline & 100 & - & 0.5058 & - & 0.6054 & - & 1.0804 \\
\hline
\end{tabular}

Note: Reddy [33] - Reddy's higher-order theory [multiplied by a factor $\left.\left(1+h / 2 R_{1}\right)\left(1+h / 2 R_{2},\right)\right]$.

It is observed in Table 4 that for lower values of thickness ratio $(a / h)$ present results slightly differ from the results presented by Reddy and Liu [33]. This difference may be due to the fact that the deflection results of Reddy and Liu [33] shown in Table 4 are multiplied by a factor $(1+$ $\left.h / 2 R_{1}\right)\left(1+h / 2 R_{2},\right)$. Moreover, Reddy and Liu [33] have not included the effect of twist curvature $\left(1 / R_{x y}\right)$ in their formulation. The geometry of cylindrical shell is as shown in Figure [4]. It can also be observed that with increasing values of $R_{1} / a$ and $a / h$ the deflections decrease.

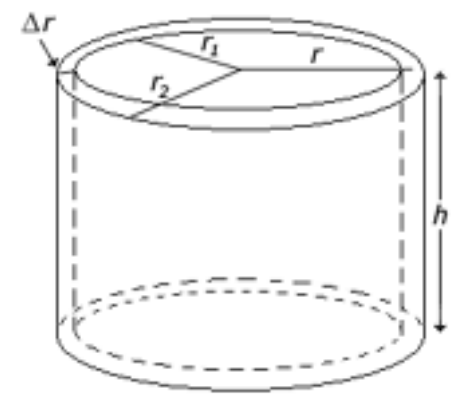

Figure 4 Perspective view of cylindrical shell panel 
The lamination scheme $\left(0^{0} / 90^{0} / 0^{0}\right)$ was found to give lesser deflection compared to other schemes for $a / h=10,100$ while for $a / h=5$, lamination scheme $\left(0^{0} / 90^{0} / 0^{0} / 90^{0} / 0^{0}\right)$ is found give lesser values for the deflections. It is also observed that the anti-symmetric lamination scheme $\left(0^{0} / 90^{0} / 0^{0} / 90^{0}\right)$ gives higher results in all the cases.

\subsection{Angle-ply cylindrical shell}

In this example, an angle-ply $(\theta /-\theta / \theta /-\theta / \theta)$ cylindrical shell panel of square plan form, simply supported at all edges and subjected to uniform transverse pressure $p$ is considered. Nondimensional central deflections obtained by using the present model are compared with the corresponding results of Bhaskar and Varadan [3]. It may be observed in Table 5 that there are differences between the two results for higher values of ply angles $(\theta)$. This may be due to the reasons that the loading considered in the two models are slightly different; and also Bhaskar and Varadan [3] have not considered the twist curvature $\left(1 / R_{x y}\right)$ in their formulation which may be significant for angle ply lamination schemes. Some new results are also presented in Table 5 . It is observed minimum deflection values corresponds to $\theta=45$ for all the cases.

Table 5 Non-dimensionalized central deflection $\bar{w}=100\left(E_{T} h^{3} / p a^{4}\right)$ of simply supported angle-ply $(\theta /-\theta / \theta /-\theta / \theta)$ cylindrical shell panel.

\begin{tabular}{|c|c|c|c|c|c|c|c|}
\hline$R_{0} / a$ & $a / h$ & Theory & $\theta=15$ & $\theta=30$ & $\theta=45$ & $\theta=60$ & $\theta=75$ \\
\hline \multirow{3}{*}{3} & \multirow{2}{*}{10} & Bhaskar and Varadan $[3]$ & 0.8507 & 0.7393 & 0.6514 & 0.7525 & 0.8769 \\
\cline { 2 - 8 } & & Present & 0.8470 & 0.7002 & 0.5994 & 0.6867 & 0.8265 \\
\cline { 2 - 8 } & 100 & Present & 0.1481 & 0.0761 & 0.0283 & 0.0664 & 0.1242 \\
\hline \multirow{2}{*}{5} & 10 & Present & 0.8589 & 0.7276 & 0.6607 & 0.7224 & 0.8511 \\
\cline { 2 - 8 } & 100 & Present & 0.2854 & 0.1668 & 0.0831 & 0.1597 & 0.2633 \\
\hline \multirow{2}{*}{10} & 10 & Present & 0.8639 & 0.7399 & 0.6903 & 0.7385 & 0.8619 \\
\cline { 2 - 8 } & 100 & Present & 0.4626 & 0.3234 & 0.2177 & 0.3202 & 0.4498 \\
\hline \multirow{2}{*}{20} & 10 & Present & 0.8652 & 0.7429 & 0.6981 & 0.7427 & 0.8647 \\
\cline { 2 - 8 } & 100 & Present & 0.5452 & 0.4197 & 0.3433 & 0.4191 & 0.5423 \\
\hline \multirow{2}{*}{50} & 10 & Present & 0.8655 & 0.7439 & 0.7004 & 0.7438 & 0.8655 \\
\cline { 2 - 8 } & 100 & Present & 0.5714 & 0.4585 & 0.4071 & 0.4604 & 0.5768 \\
\hline \multirow{2}{*}{100} & 10 & Present & 0.8656 & 0.7439 & 0.7007 & 0.7439 & 0.8656 \\
\cline { 2 - 8 } & 100 & Present & 0.5792 & 0.4662 & 0.4193 & 0.4671 & 0.5815 \\
\hline
\end{tabular}

\subsubsection{Hypar shell}

In this example cross-ply laminated hypar shells having four lamination schemes of $\left(0^{0} / 90^{0}\right)$, $\left(0^{0} / 90^{0} / 90^{0} / 0^{0}\right),\left(0^{0} / 90^{0} / 0^{0} / 90^{0}\right)$ and $\left(0^{0} / 90^{0} / 0^{0} / 90^{0} / 0^{0}\right)$ with simply supported as well as clamped boundary conditions with varying $c / a$ ratios $(0$ to 0.2$)$ are considered. The shell is subjected to uniform as well as sinusoidal loadings. It may be noted that the $c / a$ ratio is an indicator of the 
twist curvature of the hypar shell. The results are compared with those obtained by Pradyumna and Bandyopadhyay [31] and found to match very well with each other. Some new results are also presented. Lamination scheme $0^{0} / 90^{0} / 90^{0} / 0^{0}$ is found to give lesser deflections in all cases especially in case of clamped boundary (CCCC) conditions. The geometry of hypar shell is as shown in Figure [5].

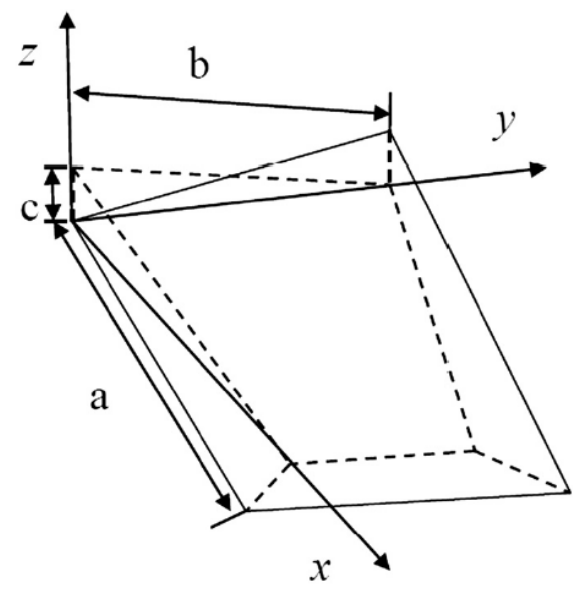

Figure 5 Perspective view of hypar shell panel

Table 6 Non-dimensional central deflection of cross-ply laminatedhypar shell panel

\begin{tabular}{|c|c|c|c|c|c|c|c|c|c|}
\hline \multirow{3}{*}{$c / a$} & \multirow{3}{*}{ Theory } & \multicolumn{8}{|c|}{ Lamination scheme } \\
\hline & & \multicolumn{2}{|c|}{$0^{\circ} / 90^{\circ}$} & \multicolumn{2}{|c|}{$0^{0} / 90^{0} / 90^{0} / 0^{0}$} & \multicolumn{2}{|c|}{$0^{0} / 90^{0} / 0^{0} / 90^{0}$} & \multicolumn{2}{|c|}{$0^{0} / 90^{\circ} / 0^{0} / 90^{\circ} / 0^{0}$} \\
\hline & & $\begin{array}{l}a / h= \\
100\end{array}$ & $\begin{array}{l}a / h= \\
10\end{array}$ & $\begin{array}{l}a / h= \\
100\end{array}$ & $\begin{array}{l}a / h= \\
10\end{array}$ & $\begin{array}{l}a / h= \\
100\end{array}$ & $\begin{array}{l}a / h= \\
10\end{array}$ & $\begin{array}{l}a / h= \\
100\end{array}$ & $\begin{array}{l}a / h= \\
10\end{array}$ \\
\hline \multicolumn{10}{|c|}{ SSSS-uniform } \\
\hline \multirow[t]{2}{*}{0} & $\begin{array}{l}\text { Pradyumna and } \\
\text { Bandyopadhyay } \\
{[31]}\end{array}$ & 16.9763 & - & 6.8436 & - & 8.1137 & - & - & - \\
\hline & Present & 16.4961 & 19.1698 & 6.8008 & 11.0546 & 8.0119 & 10.6923 & 6.8579 & 9.8175 \\
\hline \multirow[t]{2}{*}{0.05} & $\begin{array}{l}\text { Pradyumna and } \\
\text { Bandyopadhyay } \\
{[31]}\end{array}$ & 2.3744 & - & 1.9629 & - & 2.0922 & - & - & - \\
\hline & Present & 2.3696 & 17.9858 & 1.9556 & 10.6522 & 2.0861 & 10.3190 & 1.9841 & 9.5001 \\
\hline \multirow[t]{2}{*}{0.1} & $\begin{array}{l}\text { Pradyumna and } \\
\text { Bandyopadhyay } \\
{[31]}\end{array}$ & 0.6193 & - & 0.5972 & - & 0.6252 & - & - & - \\
\hline & Present & 0.6188 & 15.1714 & 0.5966 & 9.6030 & 0.6247 & 9.3402 & 0.6101 & 8.6616 \\
\hline \multirow[t]{2}{*}{0.15} & $\begin{array}{l}\text { Pradyumna and } \\
\text { Bandyopadhyay } \\
{[31]}\end{array}$ & 0.2610 & - & 0.2638 & - & 0.2767 & - & - & - \\
\hline & Present & 0.2608 & 12.0271 & 0.2637 & 8.2471 & 0.2765 & 8.0642 & 0.2714 & 7.5492 \\
\hline \multirow[t]{2}{*}{0.2} & $\begin{array}{l}\text { Pradyumna and } \\
\text { Bandyopadhyay } \\
{[31]}\end{array}$ & 0.1388 & - & 0.1434 & - & 0.1504 & - & - & - \\
\hline & Present & 0.1384 & 9.3147 & 0.1432 & 6.8835 & 0.1502 & 6.7680 & 0.1477 & 6.3972 \\
\hline
\end{tabular}


Table 6 (continued)

\begin{tabular}{|c|c|c|c|c|c|c|c|c|c|}
\hline \multicolumn{10}{|c|}{ SSSS-sinusoidal } \\
\hline \multirow[t]{2}{*}{0} & $\begin{array}{l}\text { Pradyumna and } \\
\text { Bandyopadhyay } \\
{[31]}\end{array}$ & 10.6524 & - & 4.3441 & - & 5.0857 & - & - & - \\
\hline & Present & 10.3521 & 12.1582 & 4.3160 & 7.1463 & 5.0214 & 6.8644 & 4.3216 & 6.3447 \\
\hline \multirow[t]{2}{*}{0.05} & $\begin{array}{l}\text { Pradyumna and } \\
\text { Bandyopadhyay } \\
{[31]}\end{array}$ & 1.6785 & - & 1.3511 & - & 1.3866 & - & - & - \\
\hline & Present & 1.6714 & 11.4372 & 1.3453 & 6.9039 & 1.3819 & 6.6391 & 1.3310 & 6.1540 \\
\hline \multirow[t]{2}{*}{0.1} & $\begin{array}{l}\text { Pradyumna and } \\
\text { Bandyopadhyay } \\
{[31]}\end{array}$ & 0.5672 & - & 0.4966 & - & 0.4781 & - & - & - \\
\hline & Present & 0.5654 & 9.7232 & 0.4956 & 6.2718 & 0.4771 & 6.0483 & 0.4781 & 5.6491 \\
\hline \multirow[t]{2}{*}{0.15} & $\begin{array}{l}\text { Pradyumna and } \\
\text { Bandyopadhyay } \\
{[31]}\end{array}$ & 0.3167 & - & 0.2716 & - & 0.2545 & - & - & - \\
\hline & Present & 0.3158 & 7.8083 & 0.2712 & 5.4550 & 0.2539 & 5.2783 & 0.2575 & 4.9799 \\
\hline \multirow[t]{2}{*}{0.2} & $\begin{array}{l}\text { Pradyumna and } \\
\text { Bandyopadhyay } \\
{[31]}\end{array}$ & 0.2180 & - & 0.1800 & - & 0.1680 & - & - & - \\
\hline & Present & 0.2173 & 6.1563 & 0.1797 & 4.6336 & 0.1675 & 4.4964 & 0.1698 & 4.2870 \\
\hline \multicolumn{10}{|c|}{ CCCC-uniform } \\
\hline \multirow[t]{2}{*}{0} & \begin{tabular}{|l} 
Pradyumna and \\
Bandyopadhyay \\
{$[31]$}
\end{tabular} & 3.9672 & - & 1.4859 & - & 1.7894 & - & - & - \\
\hline & Present & 3.9276 & 5.8701 & 1.4767 & 4.8050 & 1.7738 & 4.0677 & 1.4785 & 4.0236 \\
\hline \multirow[t]{2}{*}{0.05} & $\begin{array}{l}\text { Pradyumna and } \\
\text { Bandyopadhyay } \\
{[31]}\end{array}$ & 1.3371 & - & 0.8459 & - & 0.9640 & - & - & - \\
\hline & Present & 1.3349 & 5.7104 & 0.8432 & 4.6902 & 0.9606 & 3.9857 & 0.8585 & 3.9424 \\
\hline \multirow[t]{2}{*}{0.1} & $\begin{array}{l}\text { Pradyumna and } \\
\text { Bandyopadhyay } \\
{[31]}\end{array}$ & 0.3901 & - & 0.3451 & - & 0.3791 & - & - & - \\
\hline & Present & 0.3923 & 5.2770 & 0.3455 & 4.3748 & 0.3797 & 3.7574 & 0.3588 & 3.7162 \\
\hline \multirow[t]{2}{*}{0.15} & $\begin{array}{l}\text { Pradyumna and } \\
\text { Bandyopadhyay } \\
{[31]}\end{array}$ & 0.1576 & - & 0.1613 & - & 0.1732 & - & - & - \\
\hline & Present & 0.1589 & 4.6781 & 0.1619 & 3.9289 & 0.1741 & 3.4269 & 0.1693 & 3.3887 \\
\hline \multirow[t]{2}{*}{0.2} & $\begin{array}{l}\text { Pradyumna and } \\
\text { Bandyopadhyay } \\
{[31]}\end{array}$ & 0.0805 & - & 0.0879 & - & 0.0917 & - & - & - \\
\hline & Present & 0.0810 & 4.0268 & 0.0883 & 3.4307 & 0.0924 & 3.0460 & 0.0918 & 3.0114 \\
\hline
\end{tabular}


Table 6 (continued)

\begin{tabular}{|c|c|c|c|c|c|c|c|c|c|}
\hline \multicolumn{10}{|c|}{ CCCC-sinusoidal } \\
\hline \multirow[t]{2}{*}{0} & $\begin{array}{l}\text { Pradyumna and Ban- } \\
\text { dyopadhyay [31] }\end{array}$ & 2.8703 & - & 1.0967 & - & 1.2944 & - & - & - \\
\hline & Present & 2.8445 & 4.2399 & 1.0909 & 3.4731 & 1.2847 & 2.9326 & 1.0819 & 2.9112 \\
\hline \multirow[t]{2}{*}{0.05} & $\begin{array}{l}\text { Pradyumna and Ban- } \\
\text { dyopadhyay [31] }\end{array}$ & 1.0168 & - & 0.6440 & - & 0.7138 & - & - & - \\
\hline & Present & 1.0140 & 4.1300 & 0.6418 & 3.3949 & 0.7115 & 2.8770 & 0.6430 & 2.8561 \\
\hline \multirow[t]{2}{*}{0.1} & $\begin{array}{l}\text { Pradyumna and Ban- } \\
\text { dyopadhyay [31] }\end{array}$ & 0.3335 & - & 0.2826 & - & 0.2988 & - & - & - \\
\hline & Present & 0.3337 & 3.8316 & 0.2424 & 3.1800 & 0.2989 & 2.7220 & 0.2853 & 2.7024 \\
\hline \multirow[t]{2}{*}{0.15} & $\begin{array}{l}\text { Pradyumna and Ban- } \\
\text { dyopadhyay [31] }\end{array}$ & 0.1524 & - & 0.1433 & - & 0.1484 & - & - & - \\
\hline & Present & 0.1526 & 3.4189 & 0.1433 & 2.8757 & 0.1485 & 2.4973 & 0.1451 & 2.4797 \\
\hline \multirow[t]{2}{*}{0.2} & $\begin{array}{l}\text { Pradyumna and Ban- } \\
\text { dyopadhyay [31] }\end{array}$ & 0.0852 & - & 0.0837 & - & 0.0836 & - & - & - \\
\hline & Present & 0.0853 & 2.9694 & 0.0837 & 2.5350 & 0.0856 & 2.2380 & 0.0847 & 2.2225 \\
\hline
\end{tabular}

\subsection{Analysis of laminated composite skew shell}

In this section some examples of laminated composite skew hypar and cylindrical shells are studied using the present FE model based on HSDT.

\subsubsection{Skew Hypar shell}

Skew hypar shells $(b / a=1)$ having different boundary conditions are considered in this example taking three different lamination schemes $\left(0^{0} / 90^{0}, 0^{0} / 90^{0} / 0^{0}, 0^{0} / 90^{0} / 0^{0} / 90^{0}\right)$ and varying $c / a$ ratio $(0.0,0.1,0.2)$ as well as $a / h$ ratio $(10,100)$. Skew angles are varied from $0^{0}$ to $45^{0}$. Nondimensional central deflections $\left(\bar{w}=\left(\frac{10^{3} w h^{3} E_{2}}{q_{0} a^{4}}\right)\right)$ and stresses obtained by using the present FE model are shown in Table 7 and Table 8 respectively. The present results for $c / a=0$, representing plate geometry are compared with the corresponding results obtained by Chakrabartiet. al [5] for simply supported skew composite plates. It may be observed from Table 7 and 8 that the present results are matching quite well with those obtained by Chakrabarti et al.. [5]. The present model is therefore used to generate other new results. It is observed that the deflection values tend to decrease with increase in $c / a$ ratio as well as $a / h$ ratio. In this case of skew hypar shell, lamination scheme $\left(0^{0} / 90^{\circ} / 0^{0} / 90^{0}\right)$ was found to give minimum central deflections. Thin shells $(a / h=100)$ with clamped boundary condition $(\mathrm{CCCC})$ are found to give minimum deflections in all the cases listed in Table 7. Non-dimensional stresses for the same problem of hypar shell are also presented in Table $8(a / h=100)$. In-plane normal stresses and transverse shear stress are non-dimensionalized using following factors: 


$$
\begin{gathered}
\bar{\sigma}_{x}=\sigma_{x}\left(\frac{a}{2}, \frac{b}{2},-\frac{h}{2}\right) h^{2} / q_{0} a^{2}, \bar{\sigma}_{y}=\sigma_{y}\left(\frac{a}{2}, \frac{b}{2}, z\right) h^{2} / q_{0} a^{2} \\
(N=2, z=h / 2 ; N=3, z=h / 6 ; N=4, z=h / 4), \bar{\tau}_{x y}=\tau_{x y}\left(0,0,-\frac{h}{2}\right) h^{2} / q_{0} a^{2}
\end{gathered}
$$

\begin{tabular}{|c|c|c|c|c|c|c|c|c|}
\hline \multirow{3}{*}{$\begin{array}{l}\text { Boundary con- } \\
\text { dition }\end{array}$} & \multirow{3}{*}{$c / a$} & \multirow{3}{*}{$\begin{array}{l}\text { Skew } \\
\text { angle }\end{array}$} & \multicolumn{6}{|c|}{ Lamination scheme } \\
\hline & & & \multicolumn{2}{|c|}{$0^{0} / 90^{0}$} & \multicolumn{2}{|c|}{$0^{0} / 90^{0} / 0^{0}$} & \multicolumn{2}{|c|}{$0^{0} / 90^{0} / 0^{0} / 90^{0}$} \\
\hline & & & $\begin{array}{l}a / h \\
=10\end{array}$ & $a / h=100$ & $a / h=10$ & $a / h=100$ & $a / h=10$ & $a / h=100$ \\
\hline \multirow{16}{*}{ SSSS } & \multirow{8}{*}{0.0} & \multirow{2}{*}{$0^{0}$} & 19.2188 & 16.9637 & 10.9812 & 6.7064 & 10.6967 & 8.1081 \\
\hline & & & - & - & $10.9117^{1}$ & 6.7168 & - & - \\
\hline & & \multirow{2}{*}{$15^{0}$} & 16.5631 & 14.2388 & 10.4300 & 6.4294 & 9.4613 & 6.8517 \\
\hline & & & - & - & $10.3669^{1}$ & 6.4392 & - & - \\
\hline & & \multirow{2}{*}{$30^{0}$} & 10.7202 & 8.6394 & 8.6613 & 5.4608 & 6.4902 & 4.1722 \\
\hline & & & - & - & $8.6217^{1}$ & 5.4708 & - & - \\
\hline & & \multirow{2}{*}{$45^{0}$} & 5.2223 & 3.7667 & 5.7181 & 3.6190 & 3.4184 & 1.8098 \\
\hline & & & - & - & $5.7105^{1}$ & 3.6333 & - & - \\
\hline & \multirow{4}{*}{0.1} & $0^{0}$ & 15.1721 & 0.6188 & 9.4652 & 0.5680 & 9.3404 & 0.6247 \\
\hline & & $15^{0}$ & 13.9406 & 0.5797 & 8.9882 & 0.5505 & 8.4446 & 0.5890 \\
\hline & & $30^{\circ}$ & 9.8189 & 0.5580 & 7.6182 & 0.5364 & 6.0453 & 0.5487 \\
\hline & & $45^{0}$ & 5.0687 & 0.5756 & 5.2683 & 0.5430 & 3.3177 & 0.5016 \\
\hline & \multirow{4}{*}{0.2} & $0^{0}$ & 9.3148 & 0.1384 & 6.7769 & 0.1358 & 6.7681 & 0.1502 \\
\hline & & $15^{0}$ & 8.9257 & 0.1237 & 6.4289 & 0.1326 & 6.2558 & 0.1387 \\
\hline & & $30^{\circ}$ & 7.1747 & 0.1203 & 5.6522 & 0.1296 & 4.8556 & 0.1325 \\
\hline & & $45^{0}$ & 4.3850 & 0.1364 & 4.3095 & 0.1399 & 2.9727 & 0.1416 \\
\hline \multirow{12}{*}{$\mathrm{CCCC}$} & \multirow{4}{*}{0.0} & $0^{0}$ & 6.2088 & 3.9552 & 5.2198 & 1.4184 & 4.3159 & 1.7830 \\
\hline & & $15^{0}$ & 5.6912 & 3.5419 & 4.9871 & 1.3899 & 4.0084 & 1.6007 \\
\hline & & $30^{\circ}$ & 4.2922 & 2.4602 & 4.2252 & 1.2692 & 3.1558 & 1.1183 \\
\hline & & $45^{\circ}$ & 2.5206 & 1.1936 & 2.8971 & 0.9582 & 2.0114 & 0.5458 \\
\hline & \multirow{4}{*}{0.1} & $0^{0}$ & 5.3198 & 0.3923 & 4.4877 & 0.3269 & 3.8027 & 0.3797 \\
\hline & & $15^{0}$ & 4.9039 & 0.3916 & 4.3088 & 0.3268 & 3.5443 & 0.3712 \\
\hline & & $30^{\circ}$ & 3.7603 & 0.3832 & 3.7114 & 0.3263 & 2.8215 & 0.3388 \\
\hline & & $45^{0}$ & 2.2386 & 0.3395 & 2.6144 & 0.3135 & 1.8189 & 0.2582 \\
\hline & \multirow{4}{*}{0.2} & $0^{0}$ & 4.0479 & 0.0810 & 3.4924 & 0.0882 & 3.0735 & 0.0924 \\
\hline & & $15^{0}$ & 3.7987 & 0.0828 & 3.3809 & 0.0879 & 2.8991 & 0.0933 \\
\hline & & $30^{\circ}$ & 3.0725 & 0.0879 & 3.0008 & 0.0879 & 2.3943 & 0.0951 \\
\hline & & $45^{0}$ & 1.9781 & 0.0945 & 2.2423 & 0.0909 & 1.6315 & 0.0927 \\
\hline
\end{tabular}

Table 7 Non-dimensional central deflections of a laminated composite hypar shell panel subjected to uniform loading $(b / a=1)$ 
Table 7 (continued)

\begin{tabular}{|c|c|c|c|c|c|c|c|c|}
\hline \multirow{12}{*}{ SCSC } & \multirow{4}{*}{0.0} & $0^{0}$ & 9.9870 & 7.2803 & 7.2947 & 2.7499 & 6.3726 & 3.3415 \\
\hline & & $15^{0}$ & 8.9476 & 6.3348 & 6.9529 & 2.6690 & 5.8152 & 2.9199 \\
\hline & & $30^{\circ}$ & 6.4114 & 4.2032 & 5.8512 & 2.3629 & 4.3639 & 1.9459 \\
\hline & & $45^{0}$ & 3.5369 & 1.9953 & 3.9673 & 1.6895 & 2.5920 & 0.9269 \\
\hline & \multirow{4}{*}{0.1} & $0^{0}$ & 8.2657 & 0.4209 & 6.2159 & 0.3801 & 5.5637 & 0.4322 \\
\hline & & $15^{0}$ & 7.5967 & 0.4223 & 5.9545 & 0.3798 & 5.1347 & 0.4255 \\
\hline & & $30^{\circ}$ & 5.7087 & 0.4322 & 5.1217 & 0.3889 & 3.9584 & 0.4085 \\
\hline & & $45^{0}$ & 3.2650 & 0.4374 & 3.6102 & 0.4034 & 2.4162 & 0.3546 \\
\hline & \multirow{4}{*}{0.2} & $0^{0}$ & 5.6746 & 0.0827 & 4.5737 & 0.0928 & 4.2349 & 0.0968 \\
\hline & & $15^{0}$ & 5.3960 & 0.0856 & 4.4209 & 0.0923 & 3.9914 & 0.0984 \\
\hline & & $30^{\circ}$ & 4.4532 & 0.0935 & 3.9627 & 0.0946 & 3.2720 & 0.1035 \\
\hline & & $45^{0}$ & 2.8774 & 0.1103 & 3.0405 & 0.1068 & 2.1736 & 0.1122 \\
\hline
\end{tabular}

Results of these rows corresponds to Chakrabarti et al. [5].

Table 8 Non-dimensional stresses of a laminated composite hypar shell panel subjected to uniform loading $(b / a=1, a / h=100)$

\begin{tabular}{|c|c|c|c|c|c|c|c|c|c|c|}
\hline \multirow{3}{*}{$c / a$} & \multirow{3}{*}{$\begin{array}{l}\text { Skew } \\
\text { angle }\end{array}$} & \multicolumn{9}{|c|}{ Laminationscheme } \\
\hline & & \multicolumn{3}{|c|}{$0^{0} / 90^{0}$} & \multicolumn{3}{|c|}{$0^{0} / 90^{0} / 0^{0}$} & \multicolumn{3}{|c|}{$0^{0} / 90^{0} / 0^{0} / 90^{0}$} \\
\hline & & $\bar{\sigma}_{x}$ & $\bar{\sigma}_{y}$ & $\bar{\tau}_{x y}$ & $\bar{\sigma}_{x}$ & $\bar{\sigma}_{y}$ & $\bar{\tau}_{x y}$ & $\bar{\sigma}_{x}$ & $\bar{\sigma}_{y}$ & $\bar{\tau}_{x y}$ \\
\hline \multicolumn{11}{|c|}{ Simplysupported (SSSS) } \\
\hline \multirow{4}{*}{0.0} & $0^{0}$ & 1.0762 & -1.0762 & -0.0940 & 0.8094 & 0.1937 & -0.0432 & 0.7374 & 0.7005 & -0.0447 \\
\hline & $15^{0}$ & 0.9496 & -0.9598 & -0.0473 & 0.7757 & 0.2196 & -0.0270 & 0.6464 & 0.6262 & -0.0169 \\
\hline & $30^{\circ}$ & 0.6435 & -0.7258 & -0.0053 & 0.6597 & 0.2807 & -0.0136 & 0.4344 & 0.4696 & -0.0014 \\
\hline & $45^{0}$ & 0.3200 & -0.4969 & 0.0027 & 0.4482 & 0.3193 & -0.0033 & 0.2158 & 0.3190 & 0.0007 \\
\hline \multirow{4}{*}{0.1} & $0^{0}$ & 0.0244 & -0.0244 & -0.0237 & 0.0614 & 0.0051 & -0.0234 & 0.0448 & 0.0425 & -0.0229 \\
\hline & $15^{0}$ & 0.0047 & -0.0248 & -0.0058 & 0.0472 & 0.0037 & -0.0047 & 0.0288 & 0.0424 & -0.0034 \\
\hline & $30^{\circ}$ & -0.0209 & -0.0334 & -0.0029 & 0.0284 & 0.0094 & -0.0029 & 0.0094 & 0.0505 & -0.0014 \\
\hline & $45^{0}$ & -0.0390 & -0.0681 & -0.0014 & 0.0123 & 0.0330 & -0.0031 & -0.0019 & 0.0810 & -0.0014 \\
\hline \multirow{4}{*}{0.2} & $0^{0}$ & 0.0019 & -0.0019 & -0.0109 & 0.0123 & -0.0012 & -0.0112 & 0.0060 & 0.0057 & -0.0110 \\
\hline & $15^{0}$ & -0.0079 & -0.0016 & -0.0028 & 0.0051 & -0.0009 & -0.0021 & -0.0029 & 0.0065 & -0.0016 \\
\hline & $30^{0}$ & -0.0211 & -0.0024 & -0.0017 & -0.0054 & -0.0005 & -0.0015 & -0.0152 & 0.0089 & -0.0008 \\
\hline & $45^{0}$ & -0.0379 & -0.0112 & -0.0009 & -0.0161 & 0.0046 & -0.0018 & -0.0273 & 0.0201 & -0.0009 \\
\hline \multicolumn{11}{|c|}{ Clamped (CCCC) } \\
\hline \multirow{4}{*}{0.0} & $0^{0}$ & 0.4036 & -0.4036 & 0 & 0.2788 & 0.0406 & 0 & 0.2592 & 0.2448 & 0 \\
\hline & $15^{0}$ & 0.3647 & -0.3897 & 0 & 0.2728 & 0.0529 & 0 & 0.2337 & 0.2367 & 0 \\
\hline & $30^{\circ}$ & 0.2651 & -0.3410 & 0 & 0.2479 & 0.0880 & 0 & 0.1688 & 0.2077 & 0 \\
\hline & $45^{0}$ & 0.1471 & -0.2508 & 0 & 0.1879 & 0.1282 & 0 & 0.0932 & 0.1529 & 0 \\
\hline \multirow{4}{*}{0.1} & $0^{0}$ & 0.0134 & -0.0134 & 0 & 0.0530 & -0.0045 & 0 & 0.0369 & 0.0348 & 0 \\
\hline & $15^{0}$ & 0.0126 & -0.0179 & 0 & 0.0510 & -0.0055 & 0 & 0.0347 & 0.0383 & 0 \\
\hline & $30^{0}$ & 0.0148 & -0.0329 & 0 & 0.0486 & 0.0018 & 0 & 0.0328 & 0.0500 & 0 \\
\hline & $45^{0}$ & 0.0202 & -0.0604 & 0 & 0.0450 & 0.0244 & 0 & 0.0310 & 0.0658 & 0 \\
\hline \multirow{4}{*}{0.2} & $0^{0}$ & -0.0042 & 0.0042 & 0 & 0.0065 & -0.0014 & 0 & 0 & -0.0001 & 0 \\
\hline & $15^{0}$ & -0.0043 & 0.0045 & 0 & 0.0059 & -0.0027 & 0 & -0.0005 & 0.0010 & 0 \\
\hline & $30^{\circ}$ & -0.0037 & 0.0027 & 0 & 0.0053 & -0.0041 & 0 & 0.0004 & 0.0055 & 0 \\
\hline & $45^{0}$ & -0.0023 & -0.0073 & 0 & 0.0046 & -0.0014 & 0 & 0.0029 & 0.0171 & 0 \\
\hline
\end{tabular}


Table 8 (continued)

\begin{tabular}{|l|l|l|l|l|l|l|l|l|l|l|}
\hline \multicolumn{2}{|l|}{ Simply supported-Clamped (SCSC) } \\
\hline \multirow{4}{*}{0.0} & $0^{0}$ & 0.5591 & -0.5591 & -0.0609 & 0.4056 & 0.0840 & -0.0273 & 0.3686 & 0.3532 & -0.0282 \\
\cline { 2 - 11 } & $15^{0}$ & 0.4948 & -0.5262 & -0.0331 & 0.3929 & 0.1036 & -0.0176 & 0.3221 & 0.3364 & -0.0116 \\
\cline { 2 - 11 } & $30^{0}$ & 0.3534 & -0.4368 & -0.0048 & 0.3466 & 0.1493 & -0.0095 & 0.2261 & 0.2834 & -0.0013 \\
\cline { 2 - 11 } & $45^{0}$ & 0.1856 & -0.3123 & 0.0013 & 0.2495 & 0.1916 & -0.0026 & 0.1181 & 0.2076 & 0.0004 \\
\hline \multirow{5}{*}{0.1} & $0^{0}$ & 0.0047 & -0.0125 & -0.0191 & 0.0453 & -0.0148 & -0.0182 & 0.0248 & 0.0231 & -0.0158 \\
\cline { 2 - 11 } & $15^{0}$ & -0.0079 & -0.0193 & -0.0078 & 0.0356 & -0.0180 & -0.0066 & 0.0132 & 0.0255 & -0.0042 \\
\cline { 2 - 10 } & $30^{0}$ & -0.0250 & -0.0359 & -0.0028 & 0.0223 & -0.0092 & -0.0035 & 0.0001 & 0.0395 & -0.0011 \\
\cline { 2 - 10 } & $45^{0}$ & -0.0375 & -0.0642 & -0.0002 & 0.0089 & 0.0214 & -0.0019 & -0.0069 & 0.0677 & -0.0323 \\
\hline \multirow{5}{*}{0.2} & $0^{0}$ & -0.0052 & 0.0044 & -0.0106 & 0.0051 & -0.0057 & -0.0099 & -0.0028 & -0.0029 & -0.0089 \\
\cline { 2 - 10 } & $15^{0}$ & -0.0109 & 0.0037 & -0.0044 & 0.0005 & -0.0083 & -0.0037 & -0.0087 & -0.0024 & -0.0025 \\
\cline { 2 - 10 } & $30^{0}$ & -0.0210 & -0.0003 & -0.0018 & -0.0071 & -0.0097 & -0.0020 & -0.0175 & 0.0013 & -0.0008 \\
\cline { 2 - 10 } & $45^{0}$ & -0.0357 & -0.0110 & -0.0003 & -0.0177 & -0.0042 & -0.0012 & -0.0267 & 0.0142 & -0.0003 \\
\hline
\end{tabular}

\subsubsection{Skew Cylindrical shell}

In this example, Cross-ply laminated skew cylindrical shells $(b / a=3)$ having symmetric lamination scheme as $\left(0^{0} / 90^{0} / 0^{0}\right)$ and anti-symmetric lamination schemes as $\left(0^{0} / 90^{0}\right),\left(0^{0} / 90^{0} / 0^{0} / 90^{0}\right)$ with simply supported and clamped boundary conditions are considered. The skew angle is varied from $0^{0}$ to $45^{0}$. These shells are subjected to uniform loading with varying $R / a(3,10,100)$ as well as $a / h(10,100)$ ratios.

In Table 9 the values of non-dimensional central deflections $(\bar{w})$ of three different lamination schemes are presented for different skew angles. It can be observed that the deflection values decrease with increase in skew angle. Also there is not much effect of $R / a$ ratio on the deflection values. The clamped boundary condition is more effective in reduction of deflection values as compared to the simply supported boundary condition. The reduction in deflection with increase in $a / h$ ratio from 10 to 100 makes thin shells more effective. The superiority of $\left(0^{0} / 90^{0} / 0^{0}\right)$ lamination scheme is observed in all the cases mentioned in Table 9.

Present results for stresses of cylindrical shell panel $(b / a=3, R / a=4)$ subjected to sinusoidal loading are shown in Table 10. Some of the present results are compared with those of Xiao-ping [39] for zero skew angle and found to be in good agreement. The lamination scheme $\left(0^{0} / 90^{0} / 0^{0}\right)$ is found to be superior. Normal stresses decrease as the value of skew angle increases. Stresses are least in the case of clamped boundary condition. In all the cases listed; values of shear stress are much lesser compared to other stresses. 
Table 9 Non-dimensional central deflections of a laminated composite cylindrical shell panel subjected to uniform loading $(b / a=3)$

\begin{tabular}{|c|c|c|c|c|c|c|c|c|}
\hline \multirow{3}{*}{$\begin{array}{l}\text { Boundary condi- } \\
\text { tion }\end{array}$} & \multirow{3}{*}{$R / a$} & \multirow{3}{*}{$\begin{array}{l}\text { Skew } \\
\text { angle }\end{array}$} & \multicolumn{6}{|c|}{ Lamination scheme } \\
\hline & & & \multicolumn{2}{|c|}{$0^{0} / 90^{0}$} & \multicolumn{2}{|c|}{$0^{0} / 90^{0} / 0^{0}$} & \multicolumn{2}{|c|}{$0^{0} / 90^{0} / 0^{0} / 90^{0}$} \\
\hline & & & $a / h=10$ & $a / h=100$ & $a / h=10$ & $a / h=100$ & $a / h=10$ & $a / h=100$ \\
\hline \multirow{12}{*}{ SSSS } & \multirow{4}{*}{3} & $0^{0}$ & 38.6423 & 17.5678 & 11.2634 & 6.2711 & 20.1208 & 11.0884 \\
\hline & & $15^{0}$ & 35.7127 & 8.7441 & 11.0503 & 4.3794 & 18.8462 & 6.4675 \\
\hline & & $30^{0}$ & 26.3440 & 2.4594 & 10.0582 & 1.7653 & 14.4127 & 2.0799 \\
\hline & & $45^{0}$ & 13.2141 & 0.4843 & 7.2277 & 0.4157 & 7.6007 & 0.4280 \\
\hline & \multirow{4}{*}{10} & $0^{0}$ & 38.4591 & 32.2695 & 10.9839 & 6.5265 & 19.8321 & 14.8302 \\
\hline & & $15^{0}$ & 35.6285 & 27.1971 & 10.8545 & 6.2772 & 18.7313 & 13.2245 \\
\hline & & $30^{0}$ & 25.9215 & 15.8484 & 10.2259 & 5.1350 & 14.6473 & 8.4976 \\
\hline & & $45^{0}$ & 12.2178 & 6.1815 & 8.2528 & 2.6949 & 7.9607 & 3.3300 \\
\hline & \multirow{4}{*}{100} & $0^{0}$ & 38.5372 & 34.3715 & 10.9568 & 6.48221 & 19.8325 & 15.0855 \\
\hline & & $15^{0}$ & 35.4921 & 31.8843 & 10.8352 & 6.4357 & 18.7187 & 14.3902 \\
\hline & & $30^{0}$ & 25.1606 & 22.6344 & 10.2421 & 6.2211 & 14.5660 & 11.1852 \\
\hline & & $45^{0}$ & 11.2650 & 9.9188 & 8.3683 & 5.3999 & 7.7924 & 5.5613 \\
\hline \multirow{12}{*}{$\mathrm{CCCC}$} & \multirow{4}{*}{3} & $0^{0}$ & 5.4914 & 0.1277 & 3.2664 & 0.0923 & 4.3743 & 0.1242 \\
\hline & & $15^{0}$ & 5.3737 & 0.1271 & 3.2430 & 0.0921 & 4.2795 & 0.1239 \\
\hline & & $30^{0}$ & 4.7629 & 0.1251 & 3.1225 & 0.0913 & 3.7558 & 0.1224 \\
\hline & & $45^{0}$ & 3.1886 & 0.1205 & 2.6770 & 0.0891 & 2.5287 & 0.1154 \\
\hline & \multirow{4}{*}{10} & $0^{0}$ & 9.3282 & 1.1821 & 4.8846 & 0.6000 & 6.6049 & 0.9538 \\
\hline & & $15^{0}$ & 8.9780 & 1.1732 & 4.8322 & 0.5977 & 6.3762 & 0.9484 \\
\hline & & $30^{0}$ & 7.3744 & 1.1221 & 4.5641 & 0.5872 & 5.2632 & 0.8985 \\
\hline & & $45^{0}$ & 4.1901 & 0.9215 & 3.6614 & 0.5508 & 3.1421 & 0.6729 \\
\hline & \multirow{4}{*}{100} & $0^{0}$ & 10.0241 & 6.3319 & 5.1342 & 1.3081 & 6.9555 & 2.8344 \\
\hline & & $15^{0}$ & 9.6189 & 6.1223 & 5.0764 & 1.2977 & 6.7008 & 2.7854 \\
\hline & & $30^{0}$ & 7.7994 & 5.0049 & 4.7805 & 1.2528 & 5.4809 & 2.3783 \\
\hline & & $45^{0}$ & 4.3241 & 2.5959 & 3.7980 & 1.1056 & 3.2191 & 1.2628 \\
\hline \multirow{12}{*}{ SCSC } & \multirow{4}{*}{3} & $0^{0}$ & 17.6312 & 6.2102 & 7.3655 & 2.3365 & 10.9063 & 4.0331 \\
\hline & & $15^{0}$ & 16.6497 & 4.0103 & 7.2339 & 1.9001 & 10.3625 & 2.8937 \\
\hline & & $30^{0}$ & 12.9507 & 1.2835 & 6.5332 & 0.9088 & 8.1242 & 1.0771 \\
\hline & & $45^{0}$ & 6.8585 & 0.2697 & 4.5251 & 0.2394 & 4.4016 & 0.2403 \\
\hline & \multirow{4}{*}{10} & $0^{0}$ & 17.7013 & 12.6187 & 7.2659 & 2.6306 & 10.8758 & 5.7734 \\
\hline & & $15^{0}$ & 16.8148 & 11.2045 & 7.1814 & 2.5585 & 10.4146 & 5.3678 \\
\hline & & $30^{0}$ & 13.1846 & 7.0018 & 6.7511 & 2.1823 & 8.4134 & 3.7366 \\
\hline & & $45^{0}$ & 6.9278 & 2.7386 & 5.3537 & 1.2625 & 4.8174 & 1.5215 \\
\hline & \multirow{4}{*}{100} & $0^{0}$ & 17.7372 & 13.5193 & 7.2558 & 2.6230 & 10.8830 & 5.8865 \\
\hline & & $15^{0}$ & 16.8055 & 12.8839 & 7.1757 & 2.6014 & 10.4203 & 5.7363 \\
\hline & & $30^{0}$ & 12.9510 & 9.9939 & 6.7728 & 2.5095 & 8.3959 & 4.7387 \\
\hline & & $45^{0}$ & 6.5691 & 4.8274 & 5.4520 & 2.1991 & 4.7650 & 2.4543 \\
\hline
\end{tabular}


Table 10 Non-dimensional stresses of laminated cylindrical shell subjected to sinusoidal loading $(b / a=3, R / a=4)$

\begin{tabular}{|c|c|c|c|c|c|c|c|c|c|c|}
\hline \multirow{3}{*}{$a / h$} & \multirow{3}{*}{ Skew angle } & \multicolumn{9}{|c|}{ Lamination scheme } \\
\hline & & \multicolumn{3}{|c|}{$0^{0} / 90^{0}$} & \multicolumn{3}{|c|}{$0^{0} / 90^{0} / 0^{0}$} & \multicolumn{3}{|c|}{$0^{0} / 90^{0} / 0^{0} / 90^{0}$} \\
\hline & & $\bar{\sigma}_{x}$ & $\bar{\sigma}_{y}$ & $\bar{\tau}_{x y}$ & $\bar{\sigma}_{x}$ & $\bar{\sigma}_{y}$ & $\bar{\tau}_{x y}$ & $\bar{\sigma}_{x}$ & $\bar{\sigma}_{y}$ & $\bar{\tau}_{x y}$ \\
\hline \multicolumn{11}{|c|}{ Simply Supported (SSSS) } \\
\hline \multirow{5}{*}{10} & \multirow[t]{2}{*}{$0^{0}$} & 1.6878 & 0.2719 & 0.0521 & 0.6930 & 0.0608 & 0.0141 & 1.1007 & 0.1842 & 0.0257 \\
\hline & & - & - & - & $0.6985^{2}$ & 0.0603 & 0.0140 & 1.100 & 0.1846 & 0.02573 \\
\hline & $15^{0}$ & 0.5902 & 0.1366 & 0.0133 & 0.2686 & 0.0395 & 0.0054 & 0.3921 & 0.0096 & 0.0034 \\
\hline & $30^{0}$ & 0.6109 & 0.3359 & 0.0009 & 0.3642 & 0.1074 & 0.0019 & 0.4122 & 0.2199 & 0.0035 \\
\hline & $45^{0}$ & 0.4967 & 0.4957 & 0.0015 & 0.4403 & 0.2503 & 0.0097 & 0.3339 & 0.3451 & 0.0012 \\
\hline \multirow{4}{*}{100} & $0^{0}$ & 0.9797 & 0.3860 & 0.0708 & 0.5553 & 0.1283 & 0.0202 & 0.8029 & 0.2496 & 0.0404 \\
\hline & $15^{0}$ & 0.1857 & 0.0875 & 0.0096 & 0.1763 & 0.0425 & 0.0047 & 0.1956 & 0.0728 & 0.0051 \\
\hline & $30^{0}$ & 0.1215 & 0.0738 & 0.0025 & 0.1495 & 0.0496 & 0.0025 & 0.1170 & 0.0754 & 0.0011 \\
\hline & $45^{0}$ & 0.0318 & 0.0507 & 0.0009 & 0.1349 & 0.0469 & 0.0016 & 0.0443 & 0.0680 & 0.0003 \\
\hline \multicolumn{11}{|c|}{ Clamped (CCCC) } \\
\hline \multirow{4}{*}{10} & $0^{0}$ & 0.2937 & 0.0547 & 0 & 0.3510 & 0.0161 & 0.0054 & 0.2022 & 0.0529 & 0 \\
\hline & $15^{0}$ & 0.0991 & 0.0330 & 0 & 0.1344 & 0.0125 & 0.0014 & 0.0688 & 0.0309 & 0 \\
\hline & $30^{0}$ & 0.1613 & 0.1197 & 0 & 0.2040 & 0.0416 & 0 & 0.1124 & 0.0959 & 0 \\
\hline & $45^{0}$ & 0.1719 & 0.2246 & 0 & 0.2727 & 0.1256 & 0 & 0.1237 & 0.1672 & 0 \\
\hline \multirow{4}{*}{100} & $0^{0}$ & 0.0070 & 0.0042 & 0 & 0.0810 & 0.0014 & 0 & 0.0099 & 0.0038 & 0 \\
\hline & $15^{0}$ & 0.0215 & 0.0034 & 0 & 0.0305 & 0.0001 & 0 & 0.0116 & 0.0008 & 0 \\
\hline & $30^{0}$ & 0.0128 & 0.0028 & 0 & 0.0509 & 0.0021 & 0 & 0.0023 & 0.0054 & 0 \\
\hline & $45^{0}$ & 0.0052 & 0.0111 & 0 & 0.0819 & 0.0045 & 0 & 0.0043 & 0.0224 & 0 \\
\hline \multicolumn{11}{|c|}{ Simply Supported-Clamped (SCSC) } \\
\hline \multirow{4}{*}{10} & $0^{0}$ & 0.9357 & 0.1408 & 0.0333 & 0.4399 & 0.0379 & 0.0122 & 0.6434 & 0.1115 & 0.0189 \\
\hline & $15^{0}$ & 0.3967 & 0.1098 & 0.0099 & 0.1968 & 0.0359 & 0.0041 & 0.2733 & 0.0804 & 0.0026 \\
\hline & $30^{0}$ & 0.3541 & 0.1589 & 0.0010 & 0.2231 & 0.0297 & 0.0021 & 0.2389 & 0.1084 & 0.0007 \\
\hline & $45^{0}$ & 0.3238 & 0.3402 & 0.0003 & 0.3240 & 0.1523 & 0.0013 & 0.2161 & 0.2310 & 0.0005 \\
\hline \multirow{4}{*}{100} & $0^{0}$ & 0.44612 & 0.1327 & 0.0482 & 0.2829 & 0.0423 & 0.0145 & 0.3849 & 0.0895 & 0.0280 \\
\hline & $15^{0}$ & 0.0891 & 0.0652 & 0.0075 & 0.1163 & 0.0306 & 0.0031 & 0.1139 & 0.0545 & 0.0038 \\
\hline & $30^{0}$ & 0.0839 & 0.0264 & 0.0028 & 0.0898 & 0.0268 & 0.0021 & 0.0721 & 0.0139 & 0.0016 \\
\hline & $45^{0}$ & 0.0002 & 0.0034 & 0.0017 & 0.0989 & 0.0027 & 0.0019 & 0.0093 & 0.0196 & 0.0013 \\
\hline
\end{tabular}

${ }^{2}$ Results of this row corresponds to Xiao-ping [39]

\subsubsection{Angle-ply laminated skew cylindrical shell}

Angle-ply laminated $\left(45^{0} /-45^{0} / 45^{0} /-45^{0}\right)$ skew cylindrical shell $(\mathrm{b} / \mathrm{a}=3)$ is considered in this example. The shell is subjected to uniform loading with different boundary conditions such as simply supported and clamped. The skew angle is varied from $0^{0}$ to $45^{0}$. The $\mathrm{R} / \mathrm{a}(3,10,100)$ as well as a/h $(10,100)$ ratios are also varied.

Variation of non-dimensional central deflection (Figures 6a-6e) and in-plane normal stress (Figures 7a-7e) with skew angle is presented [Figures (a, b): Simply supported, Figures (c, d): Clamped and Figures (e, f):- Simply supported-clamped boundary conditions]. As in the case of 
clamped boundary condition, the in-plane shear stress was found to be zero for all the cases; variation of in-plane shear stress with skew angle is shown (Figures 8a-8d) only for two boundary conditions [Figure 8(a, b): Simply supported, 8(c, d): Simply supported-clamped boundary conditions]. From the figures it can be observed that the deflection and stresses follow the expected general trend. With increase in $R / a$ ratio, central deflection values differ significantly in case of thin shells $(a / h=100)$ as compared to those for thick shells $(a / h=10)$. Deflection and stresses tend to decrease as the skew angle increases. In Figures 8 it can be observed that in-plane shear stresses tend to attain minimum value approximately at skew angle of $30^{\circ}$.

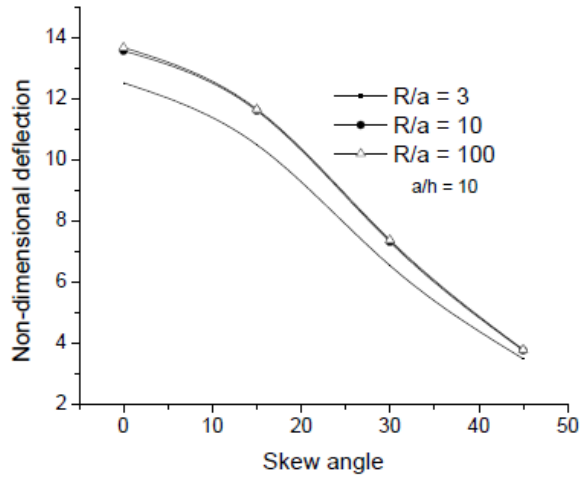

6(a)

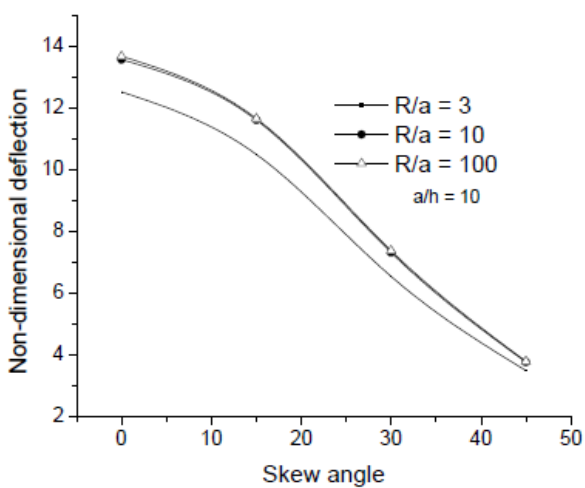

6(c)

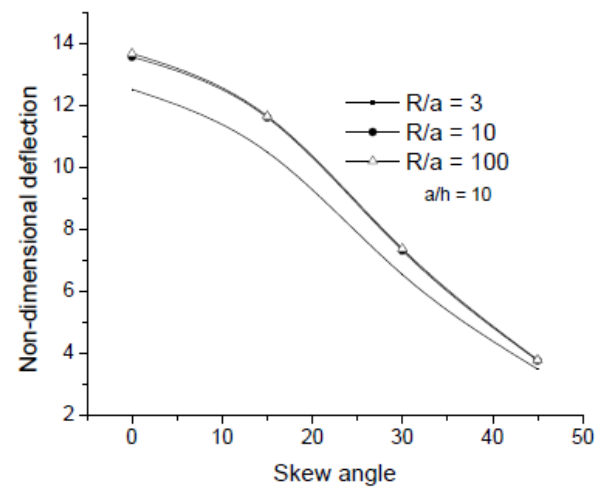

$6(\mathrm{e})$

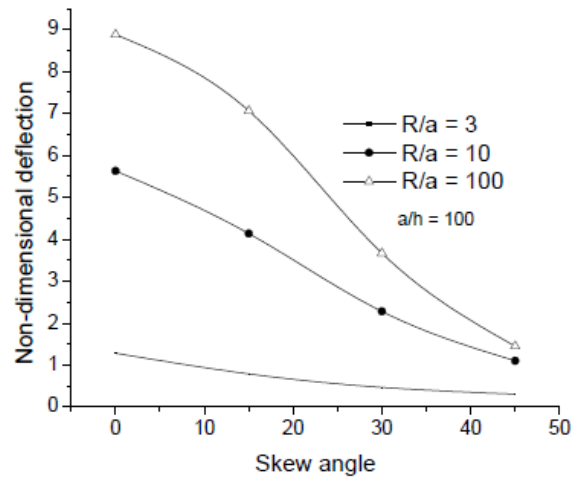

6(b)

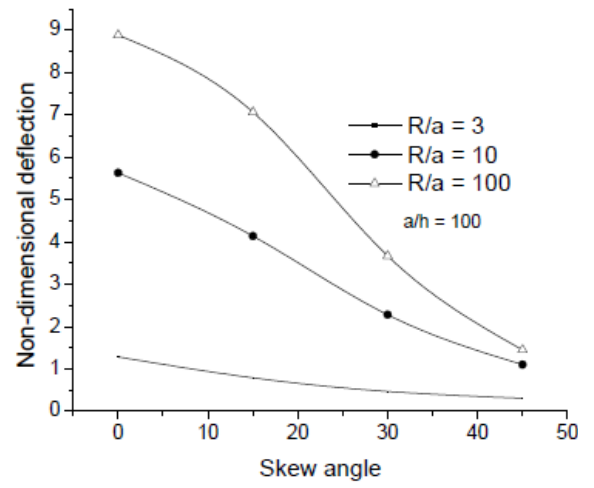

$6(\mathrm{~d})$

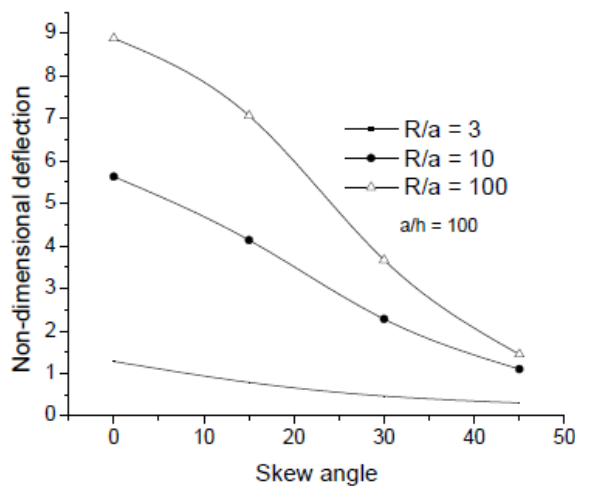

6(f)

Figure 6 Variation of non-dimensional central deflections $(\bar{w})$ of laminated angle ply skew composite cylindrical shell With skew angles 


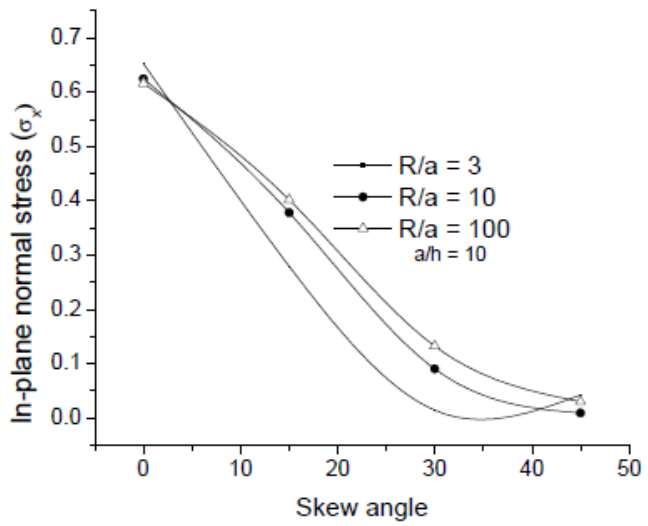

$7(\mathrm{a})$

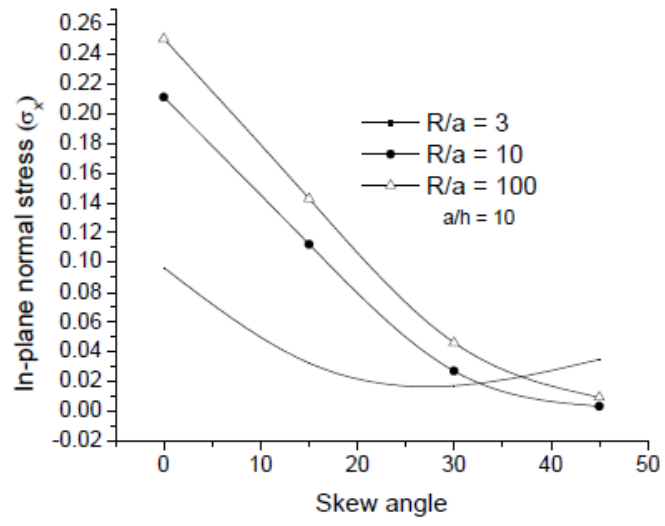

$7(\mathrm{c})$

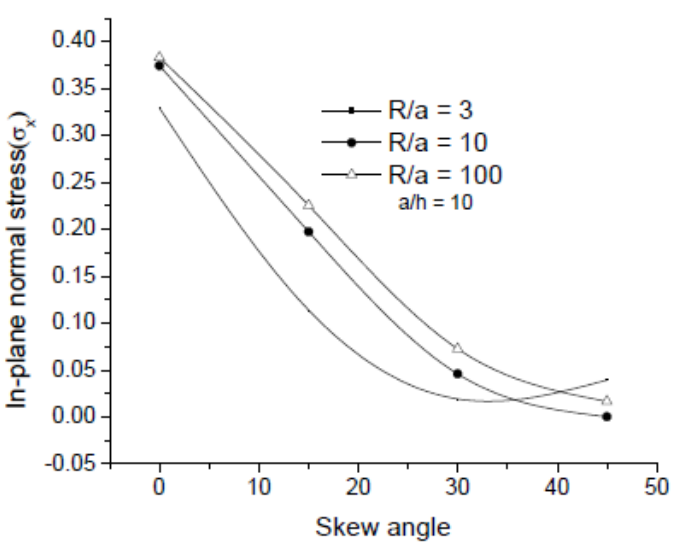

$7(\mathrm{e})$

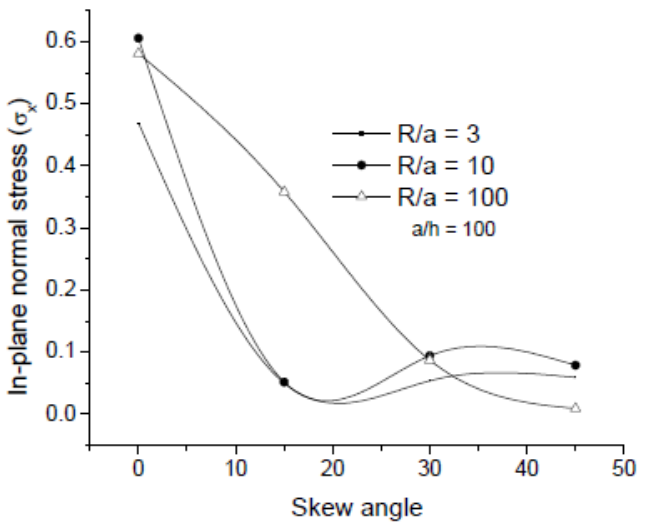

$7(\mathrm{~b})$

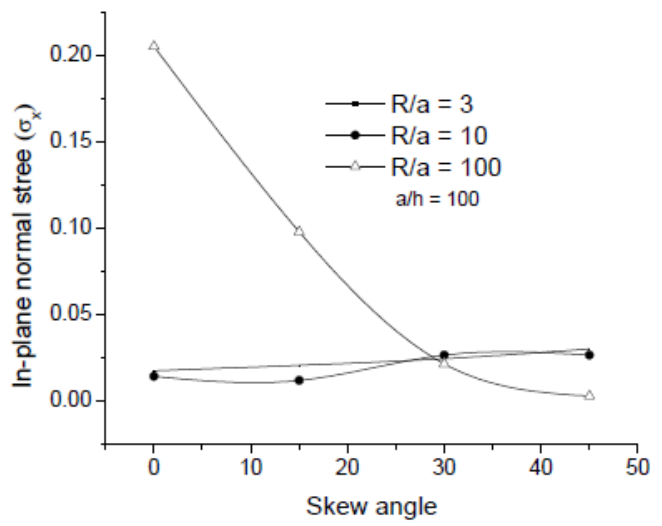

$7(\mathrm{~d})$

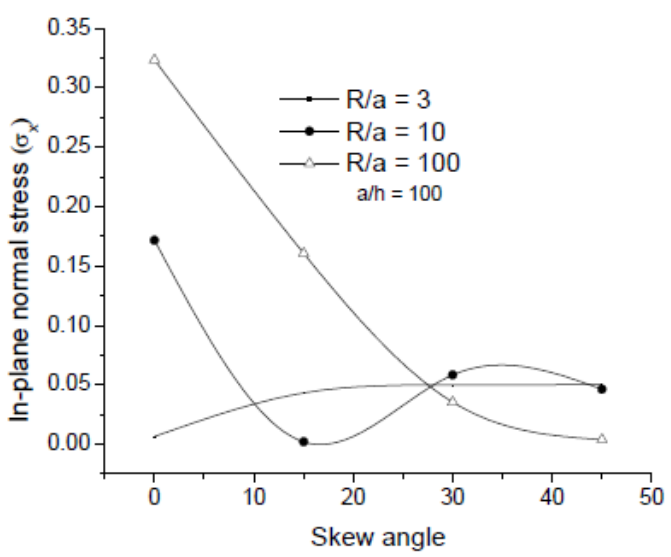

$7(\mathrm{f})$

Figure 7 Variation of non-dimensional in-plane normal stress $\left(\overline{\boldsymbol{O}}_{x}\right)$ of laminated angle ply skew composite cylindrical shell with skew angles 


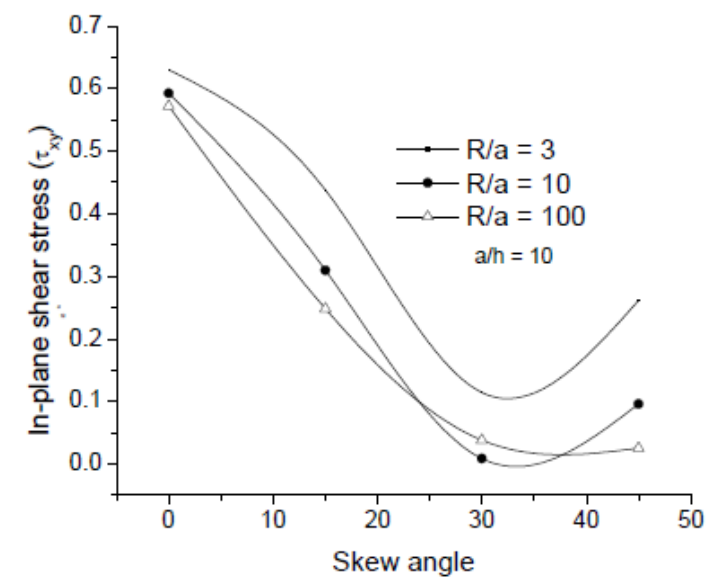

$8(\mathrm{a})$

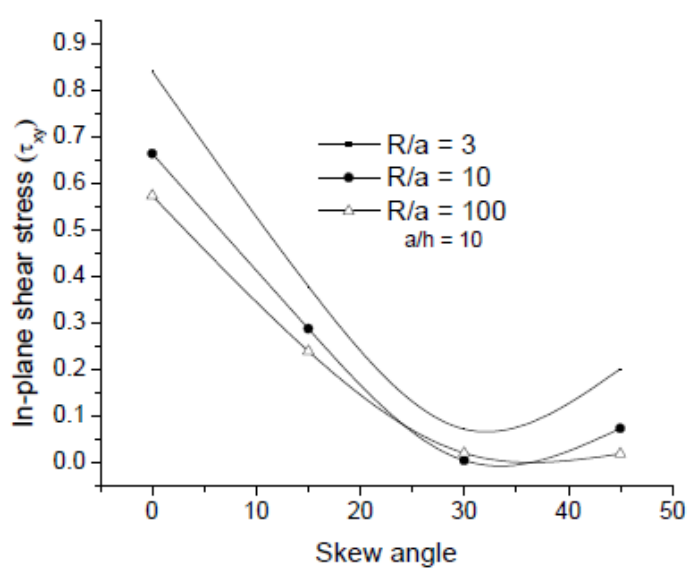

$8(\mathrm{c})$

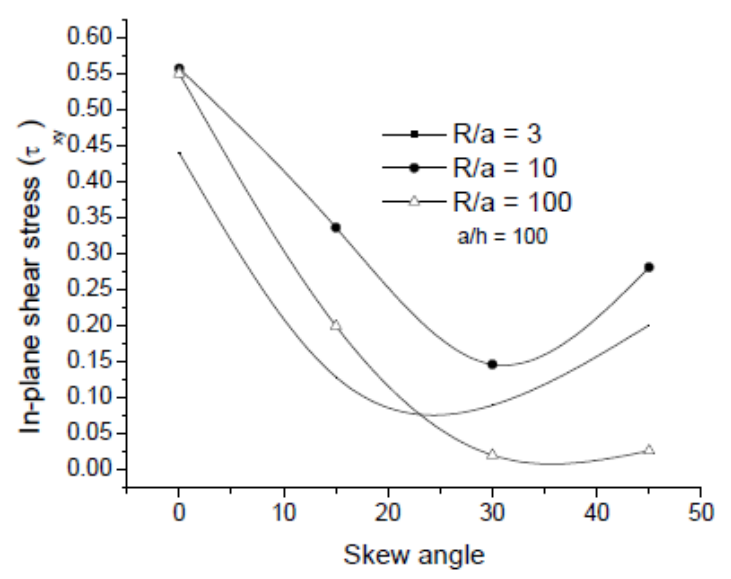

$8(\mathrm{~b})$

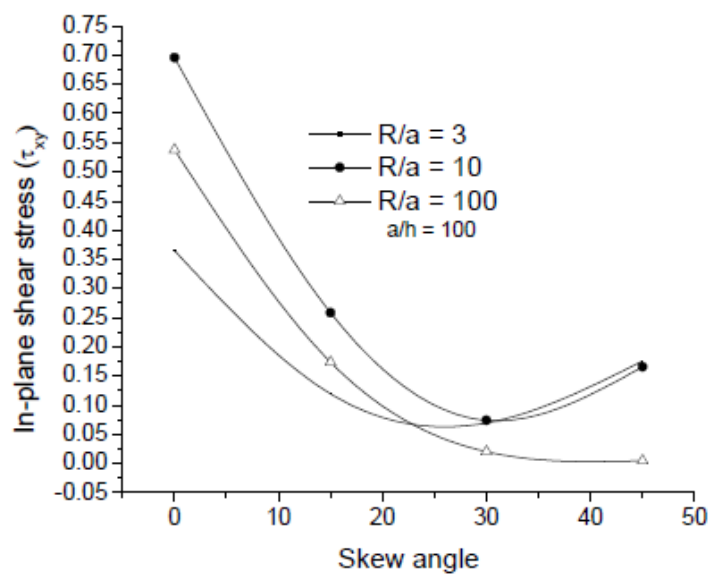

$8(\mathrm{~d})$

Figure 8 Variation of non-dimensional in-plane shear stress $\bar{\tau}_{x y}$ of laminated angle ply skew composite cylindrical shell with skew angles

\section{CONCLUSIONS}

In this paper, a new finite element model has been developed for the analysis of skew composite shells based on higher order shear deformation theory (HSDT) using a $\mathrm{C}_{0}$ formulation. In this model there is no need to include any shear correction factor. Three radii of curvatures including the cross curvature effects are also considered in the FE formulation which accounts for twisting effect of the geometry. Different shell forms considered in this study include spherical, conical, cylindrical and hypar shells. It is observed there is no result available in the literature on the present problem of skew composite shell. Therefore, many new results are generated on the static response of laminated composite skew shells considering different geometry, boundary conditions, ply orientation, loadings and skew angles which should be useful for future research.

The following general conclusions are made: 
1. Central deflection values are lesser for thin shells $(a / h=100)$ as compared to thick shells $(a / h=10)$ for all the types of shells considered in this paper.

2. The lamination scheme $0^{0} / 90^{0} / 0^{0}$ is found to give minimum central deflection values for spherical, cylindrical and hypar shells.

3. In cylindrical and spherical shells, as the $R / a$ ratio increases central deflection values decrease.

4. Laminated composite angle-ply $(\theta /-\theta / \theta /-\theta / \theta)$ cylindrical shell gives minimum deflection values corresponds to $\theta=45$ for all the cases.

5. Laminated composite skew hypar shell give minimum central deflection for lamination scheme $\left(0^{0} / 90^{0} / 0^{0} / 90^{0}\right)$.

6. In-plane normal stresses decrease as the skew angle increases in case of laminated composite skew cylindrical shell.

7. In-plane shear stresses are much lesser compared to in-plane normal stresses for both cylindrical and hypar shells.

\section{References}

[1] A. K. Aditya and J. N. Bandyopadhyay, Simplified Bending Analysis of Doubly Curved Shells, Computers \& Structures, 33(3): 781-784 (1989).

[2] C. W. Bert, Dynamics of composite and sandwich panels-Parts I and IX (corrected title). Shock Vib. Dig. 8, No. IO, 37-48 (1976); 8, No. f 1, 15-24 (1976).

[3] K. Bhaskar and T. K. Varadan, A higher-order theory for bending analysis of laminated shells of revolution, Cornputers\&Strucrures Vol. 40, No. 4, pp. 815-819, 1991.

[4] A. Bhimaraddi, A Higher Order Theory for Free Vibration Analysis of Circular Cylindrical Shells, Int. J. Solids Structures, 20(7): 623-630 (1984).

[5] A. Chakrabarti, Dr. S. K. Sengupta and Dr. A. H. Sheikh, Analysis of skew composite plates using a new triangular element based on higher order shear deformation theory,

[6] D. Chakravorty, J. N. Bandyopadhyay and P. K. Sinha, Finite Element Free Vibration Analysis of Doubly Curved Laminated Composite Shells, Journal of Sound and Vibration, 191(4): 491-504 (1996).

[7] D. Chakravorty, J. N. Bandyopadhyay and P. K. Sinha, Application of FEM on Free and Forced Vibration of Laminated Shells, ASCE Journal of Engineering Mechanics, 124(1): 1-8 (1998).

[8] M. Cho, K.Kim and M. Kim, Efficient Higher-order Shell Theory for Laminated Composites, Composite Structures, 34(2): 197-212 (1996).

[9] Chang-Koon Choi, A conoidal shell analysis by Modified isoparametric element, Computers and Structures Vol.18, No.5, pp.921-924, 1984.

[10] R. D. Cook, D. S. Malkus, M. E. Plesha and R. J. Witt, Concepts and applications of finite element analysis, Wiley, fourth edition.

[11] I.F.PintoCorreia, J.I.Barbosa, CristovaoM.MotaSoares and Carlos A. MotaSoares, A finite element semianalytical model for laminated axi-symmetric shells: statics, dynamics and buckling, Computers and Structures 76 (2000) 299-317.

[12] S. B. Dong, K. S. Pister and R. L. Taylor, On the theory of laminated anisotropic shells and plates. Jouriral ofAerospace Sciences 29 (1962).

[13] S. B. Dong and F. K. W. Tso, On a laminated orthotropic shell theory including transverse shear deformation. J. Appl. Mech. 39, 1091-1096 (1972).

[14] B. Ghosh and J. N. Bandyopadhyay, Bending Analysis of Conoidal Shells using Curved Quadratic Isoparametric Element, Computers \& Structures, 33(4): 717-728 (1989).

[15] B. Ghosh and J. N. Bandyopadhyay, Approximate Bending Analysis of Conoidal Shells Using the GalerkinMethod, Computers \& Structures, 36(5): 801-805 (1990).

[16] S. T. Gulati and F. Essenberg, Effects of anisotropy in axisymmetric cylindrical shells. Journal of Applied 
Mechanics 34, 650-666 (1967).

[17] SalilHaldar, AditiMajumdar and MihirChandar Manna, Bending of skewed cylindrical shell panels, International Journal of Computer Applications (0975-8887) Volume 1-No.8, (2010).

[18] F. B. Hildebrand, E. Reissner and G. B. Thomas, Note on the foundations of the theory of small displacements of orthotropic shells. National Advisory Comm. Aero. Tech. Notes, No. 1833 (1949).

[19] T. M. Hsu and J. T. S. Wang, A theory of laminated cylindrical shells consisting of layers of orthotropic laminae. AIAA Journal 8,(12), 2141 (1970).

[20] N. N. Huang, Influence of shear correction factors in the high\&-order shear deformation laminated shell theory. Int. J. Solids Strut. 31, 1263-1227 (1994).

[21] T. Kant and R. K. Khare, A Higher-order Facet Quadrilateral Composite Shell Element, Int. J. for Numerical Methods in Engng., 40: 4477-4499 (1997).

[22] T. Kant \& J. R. Kommineni, Geometrically non-linear analysis of symmetrically laminated composite and sandwich shells with a higher-order theory and $\mathrm{C}^{0}$ finite elements, Composite Structures 27,403-418 (1994).

[23] R. K. Khare, T. Kant and A. K. Garg, Free Vibration of Composite and Sandwich Laminates with a Higherorder Facet Shell Element, Composite Structures, 65: 405-418 (2004).

[24] K. M. Liew and C. W. Lim, A Higher-order Theory for Vibration of Doubly Curved Shallow Shells, ASME, Journal of Applied Mechanics, 63: 587-593 (1996).

[25] A. I. Lure, Statics of Thin Elastic Shells. Gostekhizdat, Moscow (1947) (in Russian).

[26] Mallikarjuna and T. Kant, A General Fibre-reinforced Composite Shell Element Based on a Refined Shear Deformation Theory, Computers \& Structures, 42(3): 381-388 (1992).

[27] J. S Moita, C. M. M. Soares and C. A. M. Soares, Buckling and Dynamic behavior of laminated composite structures using a discrete higher-order displacement model, Computers \& Structures, 73(1-5):407-423.(1999)

[28] P. M. Naghdi, A survey of recent progress in the theory of elastic shells.,Appl. Mech. Revzews 9, No. 9,365368 (1956).

[29] A. N. Nayak and J. N. Bandyopadhyay, Free Vibration Analysis and Design Aids of Stiffened Conoid Shells, ASCE J. Eng. Mech., 124(4): 419-427 (2002).

[30] A. N. Nayak, and J. N. Bandyopadhyay, Free Vibration Analysis of Laminated Stiffened Shells, ASCE J. Eng. Mech., 131(1): 100-105 (2003).

[31] S. Pradyumna and J. N. Bandyopadhyay, Static and Free Vibration Analyses of Laminated Shells using a Higher-order Theory, Journal of Reinforced Plastics and Composites published online 31 October 2007.

[32] J. N. Reddy, A simple Higher Order Theory for laminated composite plates, Journal of applied Mechanics, December 1984, Vol. 51/745.

[33] J. N. Reddy and C. F. Liu, A higher-order shear deformation theory of laminated elastic shells, International Journal of Engineering Science Vol. 23, No. 3, PP. 319-330, (1985).

[34] S.K. Singh, A. Chakrabarti, P. Bera, Sony J.S.D., An Efficient $C^{0}$ FE Model for the analysis of composites and sandwich laminates with general layup. Latin American Journal of Solids and Structures Vol. 8, No. 2, PP. 197-212, (2011).

[35] E. Reissner, Stress-strain relations in the theory of thin elastic shells. J. Math. Phys. 31, 109-119 (1952).

[36] L. T. Stavridis, Dynamic Analysis of Shallow Shells of Rectangular Base, Journal of Sound and Vibration, 218(5): 861-882 (1998).

[37] J. M. Whitney and C. T. Sun, A higher order theory for extensional motion of laminated anisotropic shells and plates. J. Sound and Vibration 30, 85 (1973).

[38] J. M. Whitney and C. T. Sun, A refined theory for laminated anisotropic cylindrical shells. Journal of Applied Mechanics 41, 47 (1974).

[39] Shu Xiao-ping, An improved simple higher-order theory for laminated composite shells, Computers and Structures Vol.60, No.3, pp. 343-350, (1996).

[40] Shu X. and L. Sun, An Improved Simple Higher-order Theory for Laminated Composite Plates, Computers\& Structures, 50(2), 231-236 (1994).

[41] T. Y. Yang, High Order Rectangular Shallow Shell Finite Element, Journal of the Engineering Mechanics Division, 99(EM1): 157-181(1973).

Latin American Journal of Solids and Structures 10(2013) $891-919$ 
[42] Y.X. Zhang, C.H. Yan, Recent developments in finite element analysis for laminated composite plates, Composite Structures 88, 147-157, (2009).

[43] J. A. Zukas and J. R. Vinson, Laminated transversely isotropic cylindrical shells. Journal of' Applied Mechanics 38, 400-407 (1971). 